\title{
A modified method of evaluating the impact of air humidity on human acceptable air temperatures in hot-humid environments
}

Article

Accepted Version

Creative Commons: Attribution-Noncommercial-No Derivative Works 4.0

Li, B., Du, C., Tan, M., Liu, H., Essah, E. and Yao, R. (2018) A modified method of evaluating the impact of air humidity on human acceptable air temperatures in hot-humid environments. Energy and Buildings, 158. pp. 393-405. ISSN 0378-7788 doi: https://doi.org/10.1016/j.enbuild.2017.09.062 Available at https://centaur.reading.ac.uk/74011/

It is advisable to refer to the publisher's version if you intend to cite from the work. See Guidance on citing.

To link to this article DOI: http://dx.doi.org/10.1016/j.enbuild.2017.09.062

Publisher: Elsevier

All outputs in CentAUR are protected by Intellectual Property Rights law, including copyright law. Copyright and IPR is retained by the creators or other copyright holders. Terms and conditions for use of this material are defined in the End User Agreement. 


\section{CentAUR}

Central Archive at the University of Reading

Reading's research outputs online 


\title{
Studies of the impact of air humidity on human acceptable temperatures in hot-humid environments
}

\author{
Baizhan $\mathrm{Li}^{1,2^{*}}$, Chenqiu Du ${ }^{1,2}$, Meilan Tan ${ }^{1,3}$, Hong Liu ${ }^{1,2}$, Emmanuel Essah ${ }^{1,4}$, \\ Runming $\mathrm{Yao}^{1,4}$ \\ ${ }^{1}$ Joint International Research Laboratory of Green Buildings and Built Environments (Ministry of \\ Education), Chongqing University, Chongqing, China. \\ ${ }^{2}$ National Centre for International Research of Low-carbon and Green Buildings (Ministry of \\ Science and Technology), Chongqing University, Chongqing, China. \\ ${ }^{3}$ College of Urban Construction, Nanjing Tech University, Nanjing, Jiangsu, China. \\ ${ }^{4}$ School of the Built Environment, University of Reading, Reading, UK. \\ Corresponding authors: baizhanli@cqu.edu.cn; r.yao@reading.ac.uk
}

\begin{abstract}
:
This research aims to investigate human thermal responses to air humidity in warm and hot environments and to evaluate the effect of humidity on human thermal comfort. 20 subjects were involved in 12 exposure experiments in a well-controlled climate chamber at three relative humidity levels $(40 \% \mathrm{RH}, 60 \% \mathrm{RH}, 80 \% \mathrm{RH})$ and four air temperature levels $\left(26^{\circ} \mathrm{C}, 28^{\circ} \mathrm{C}, 30^{\circ} \mathrm{C}, 32^{\circ} \mathrm{C}\right)$ with no much indoor airflow. The physical environmental and physiological parameters as well as subjective questionnaires were collected simultaneously during the period of experiments. The results show that in hot environments, particularly when the air temperature exceeds $30^{\circ} \mathrm{C}$, the relative humidity has a significant effect on human thermal responses both physiologically and subjectively. The Standard Effective Temperature (SET) is biased when evaluating human thermal comfort in the hot-humid environments without considering human thermal adaptation to humidity. Hence, a humidity correction coefficient $e_{R H}$ is proposed to modify the deviation of the SET under different relative humidity levels, and to quantify the effect of humidity on human acceptable air
\end{abstract}


temperatures. The modified acceptable temperature-humidity zone has been obtained using the modified method.

\section{Keywords:}

Hot-humid environment, thermal response, thermal adaptation, humidity correction coefficient, modified SET model, acceptable temperature - humidity zone.

\section{Introduction}

The impact of thermal environments on comfort and health have long been of interest for researchers[1], although it is often regarded as a main role of temperature. In reality, humidity impacts on thermal sensations. For example, according to the on-site survey in China, the relative humidity is usually above $70 \%$ in the hot-humid area[2-4], which significantly exacerbates negative impact on human thermal comfort[5].

However, the humidity is so far the most debated variable as there is almost inconsistency in how humidity is incorporated and interpreted in these studies. These studies have covered a variety of research directions from the aspects of thermal comfort to human health and from the comfortable thermal environments to the extreme ones that are heat stress-related. For example, the initial studies on indoor air humidity concentrated on improving the understanding of the effective temperature (ET)[6-8]. From the 1960s to the 1980s, quite a number of experimental studies were conducted in climate chambers to explore the effect of relative humidity on human physiological responses and thermal perceptions in a wide range of $20 \%-90 \%$. These studies had coupled with a larger temperature range $[9,10]$ (e.g. from $20^{\circ} \mathrm{C}$ to $34^{\circ} \mathrm{C}[10]$ ), moderate metabolic rate level [11-13] (e.g. from 0.95met to 2.94met [13]) and air velocity range[14, 15] (e.g. from $0.7 \mathrm{~m} / \mathrm{s}$ to $1.4 \mathrm{~m} / \mathrm{s}[15]$ ), etc. Overall, they concluded consistently that the effect of air humidity under $70 \%$ with lower temperature and metabolism was slight; while thermal discomfort increased with elevated temperature 
and metabolism. While the effect of air humidity is negligible on thermal comfort zones, research on air humidity extended to extreme thermal environments have focused on human heat stress and drawn some significant results. For example, Ronald J.[16]compared the acceptable training time of subjects and their physiological regulation with different relative humidity levels. The results showed the subjects' acceptable exposure time were significantly shorten with increased relative humidity, and their skin temperatures had significant differences between $24 \% \mathrm{RH}$ and $80 \% \mathrm{RH}$. Besides, the relative humidity in hot environments would also affect human heat tolerance[17], productivity[18] and heat acclimatization[19]. These studies explored the negative effect of high air humidity and have been well developed on the improvements [20, 21] to the international standards of heat stress [22, 23]. With the air quality and its relationship with human health being the focus, the effect of air humidity on indoor air quality and the possible pathogenicity attracted more and more researchers' interests based on field surveys. One emphasized the relations of building indoor moisture and children's respiratory disease like asthma [24-26], and the effect on the formation of organic aerosols [27, 28], as well as the volatilization of building materials [29]. Some other work focused on the negative effect of low air humidity on passengers' comfort and health in aircraft cabins, causing uncomfortable feelings of irritation in eyes, noses and throat, dryness of the skin and mucous membranes [30, 31].

Despite the widespread studies, research on identifying the effect of air humidity on thermal comfort are still far from perfect. Previous studies showed the effect of air humidity is slight within the comfort range[8, 11, 12, 32, 33]. However Nevins et al. [9] studied the human thermal responses under the 72 combined temperature and humidity experimental conditions with temperatures range from $18.9^{\circ} \mathrm{C}$ to $27.8^{\circ} \mathrm{C}$ at the interval of $1.1^{\circ} \mathrm{Cand}$ the relative humidity range from $15 \%$ to $85 \%$ at the interval of $5 \%$. Results from this study showed when the RH was decreased by $10 \%$, the acceptable air temperature could be increased by $0.3^{\circ} \mathrm{C}$ to share the same thermal sensation. Ling et al.[34] also pointed out that the impact of humidity became significant with increased air temperature if the humidity was above $70 \%$, which is in 
agreement with other studies[35, 36]. The simulated dynamic change of air humidity from Li et al.[37] also demonstrated the effect of the RH ramps (gradual change of RH in a cycle: $80 \%$ to $20 \%$ to $80 \% \mathrm{RH}$ ) was more prominent at $28^{\circ} \mathrm{C}$ than that at $20^{\circ} \mathrm{C}$ and $25{ }^{\circ} \mathrm{C}$. All these studies documented that the negative effect of $\mathrm{RH}$ outstood when combing with high air temperatures. Unfortunately, there is a paucity of research to evaluate the effect of air humidity quantitatively rather than qualitatively. Though the humidity limitation has been revised and presented in different ways in different versions of ASHRAE from 1915 [38], the humidity ratio of $0.012 \mathrm{~kg} / \mathrm{kg}$ considering the condensation and mold, has been adopted for the comfort zone since the version of ASHRAE 55-2004 [39]. In this case, the acceptable maximum relative humidity is close to $70 \%$ when the temperature is less than $25^{\circ} \mathrm{C}$.

Furthermore, these studies do not reflect the actual situation in some regions, especially for the hot-humid areas. For example, although the comfort temperature with thermal sensation of 0 (neutral) and thus the acceptable temperature range with thermal sensation of -0.5 to +0.5 have been defined in the Graphic Comfort Zone in ASHRAE 55[40], it remains unknown whether people living in hot-humid environments for a long time have the capacity to adapt to high humidity and thus have larger acceptable temperature ranges. The present comfort zone in ASHRAE 55-2013 is mainly based on the predicted model for the Predicted Mean Vote-Predicted Percentage of Dissatisfied (PMV-PPD) [40]. The PMV is originally derived from the heat balance equation under neutral conditions in which human skin temperatures and skin wetness are required to be within a comfortable range. In ISO 7730 [41], it is recommended that the PMV index should only be used for PMV values between -2 to +2 to predict the indoor thermal environments. Studies has also verified that the PMV model has a significant deviation compared with the actual thermal sensation in a number of laboratory studies in hothumid conditions[35, 36, 38, 42]. Therefore, the PMV model is not expected to be used in a hot environment.

Another commonly and extensively used model is the Standard Effective Temperature (SET) [43]which has long been used in ASHRAE Standard 55 for thermal comfort in a 
variety of thermal environments and vary depending on air temperature and humidity and other factors. It is an equivalent temperature index that assumes people in the actual environment have the same skin temperatures and skin wetness as those in an imaginary environment [40]. The SET takes into consideration of human real sweating and skin wetness and thus can be used in a wide range of environmental conditions, and has been verified to have a good relationship with human thermal sensation[3, 15].

However, some recent field studies involving human thermal adaption have discussed the deviation of the SET model in naturally ventilated environments. Gao et al. [44]argued a great difference between thermal sensation predicted by SET and the actual thermal sensation votes (TSV) from occupants and thus proposed an adaptive SET model referring to the adaptive PMV model (aPMV)[45]. Through a year-long field study in naturally ventilated buildings in hot-humid environments, Zhang et al. [3] found that the SET range corresponding to each scale of real TSV from occupants was shifted to a higher temperature by $1.5^{\circ} \mathrm{C}$ more than the SET recommended range [46]that corresponds to different thermal sensation scales. The research findings suggest that the SET model should be modified to evaluate human thermal comfort in hot-humid environments when taking into account human thermal adaptation. Therefore, some open questions remain as follows:

- Do people living in the hot-humid climates, who have been acclimatized to the higher humidity levels, have a higher tolerance for high temperature?

- Can the SET model reflect human thermal adaptation to the air humidity when being used to evaluate human thermal comfort?

- How can the effect of human thermal adaptation caused by high humidity on acceptable temperatures be quantified?

To the authors' knowledge, these questions have not been answered by the existing studies. The aim of this research is to investigate the human physiological response to, and their subjective thermal perception of, the different humidity levels through a series of human exposure experiments, and quantify the effect of humidity on the people's 
acceptable temperature ranges due to the capacity of long-term thermal adaptation and acclimatized. To achieve the aim, it is envisaged that lower acceptable temperature limit was dependent upon whether the effect of air humidity on human thermal comfort occurs under that temperature/humidity condition, which is related to whether the occupants' thermal adaptation to hot-humid occurs. Meantime the upper acceptable temperature limit was dependent upon whether the subjects' thermal sensation exceeds 0.5 under the given condition. The acceptable temperature ranges is expected to be obtained through analyzing the predicted results by the SET model, and the actual thermal sensation votes (TSV) based on the experimental data in a well-controlled climate chamber.

\section{Methods}

The quantitative analysis method of human thermal adaptation to air humidity in this study refers to that proposed by Griffiths[47]. Based on the SET model, human skin temperature and skin wetness are the essential parameters for the calculation of SET, therefore the two-node model from Gagge[48] is used to obtain the predicted SET values. Experiments with different conditions were conducted in a well-controlled climate chamber with human exposures and the data obtained are to be used for quantitative analysis.

\subsection{Climate chamber and experimental conditions}

Experiments were designed to expose subjects to the 12 designed conditions (Air Temperature: $26^{\circ} \mathrm{C}, 28^{\circ} \mathrm{C}, 30^{\circ} \mathrm{C}, 32^{\circ} \mathrm{C}$; Relative Humidity: $40 \%, 60 \%, 80 \%$ ) in a climate chamber from June to July in Chongqing and performed strictly in accordance with the Declaration of Helsinki[49]. The climate chamber with dimensions of $4 \mathrm{~m} \times 3 \mathrm{~m} \times 3 \mathrm{~m}(\mathrm{~L} \times \mathrm{W} \times \mathrm{H})$ was used to create different temperature and humidity conditions. The controlled range of temperatures in the chamber was from $10^{\circ} \mathrm{C}$ to $40^{\circ} \mathrm{C}$ within an accuracy of $\pm 0.3^{\circ} \mathrm{C}$ and from $-5^{\circ} \mathrm{C}$ to $10^{\circ} \mathrm{C}$ within an accuracy of $\pm 0.5^{\circ} \mathrm{C}$. In 
addition, the chamber environments were designed with different $\mathrm{RH}$ values from $10 \%$ to $90 \%$, with an accuracy of $\pm 5 \%$. The air supply was from a ceiling perforated plate, designed to ensure a uniform air distribution during the experiments. Also, an adjacent room (see Fig.1), with dimensions of $5.15 \mathrm{~m} \times 4.2 \mathrm{~m} \times 3 \mathrm{~m}(\mathrm{~L} \times \mathrm{W} \times \mathrm{H})$ at a temperature maintained at $26^{\circ} \mathrm{C}$ was used for the preparation work before the experiments.

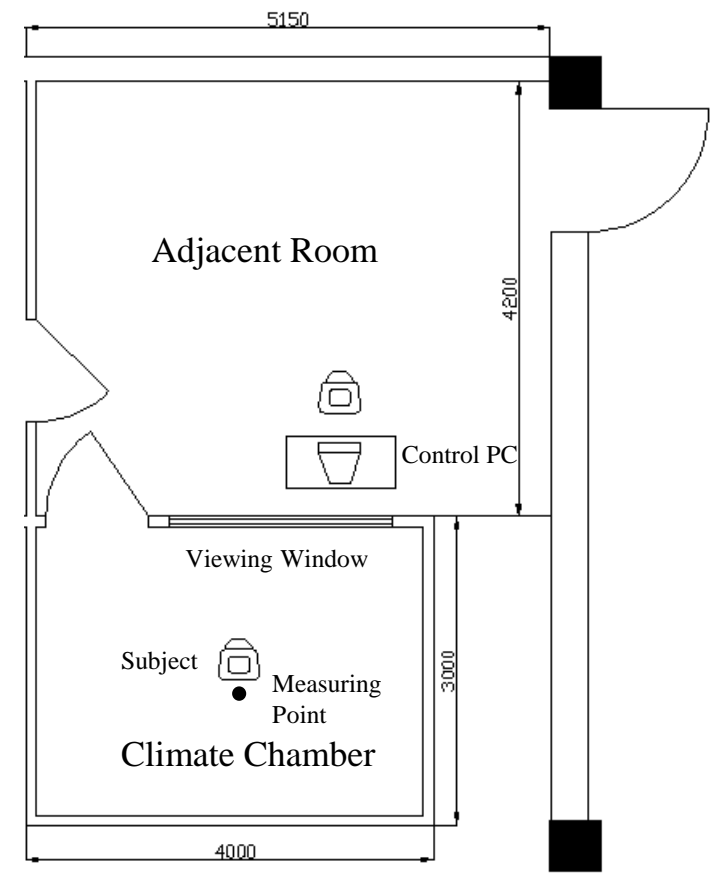

Figure 1: The floor plan of the climate chamber and the preparation room

The main aim of this study is to explore the human thermal response with two variables of air temperature and air humidity, and thus 12 conditions were created in the climate chamber with four temperature levels and three relative humidity levels (see Table 1). Considering that the effect of air humidity and occupants' thermal adaptation to humidity would take place coupling with higher temperatures, the conditions with higher air temperature of $32^{\circ} \mathrm{C}$ and air humidity of $60 \%$ and $80 \%$ are conducted. This referred to the meteorological parameters over the years in Chongqing [50] and is commonly encountered in Chongqing based on the typical climatic characteristics, namely, hot, humid, and less wind in summer. As a result, as fixed variables, the air 
velocity was controlled under $0.1 \mathrm{~m} / \mathrm{s}$ (measured at the position of $0.6 \mathrm{~m}$ above the floor and $0.5 \mathrm{~m}$ away from subjects).

The physical environmental parameters of different conditions during the experiments were measured and the averaged values are shown in Table 1. As can be seen, the thermal environments are well controlled during the experiments to meet the design requirement. Besides, due to the inner enclosure structure in the chamber, the globe temperature was much close to the air temperature, the difference of which was below $0.5^{\circ} \mathrm{C}$. Therefore, this research mainly focused on the air temperature and assumed the radiant temperature was equal to the air temperature.

Table 1: Measured parameters in the climate chamber during experiments

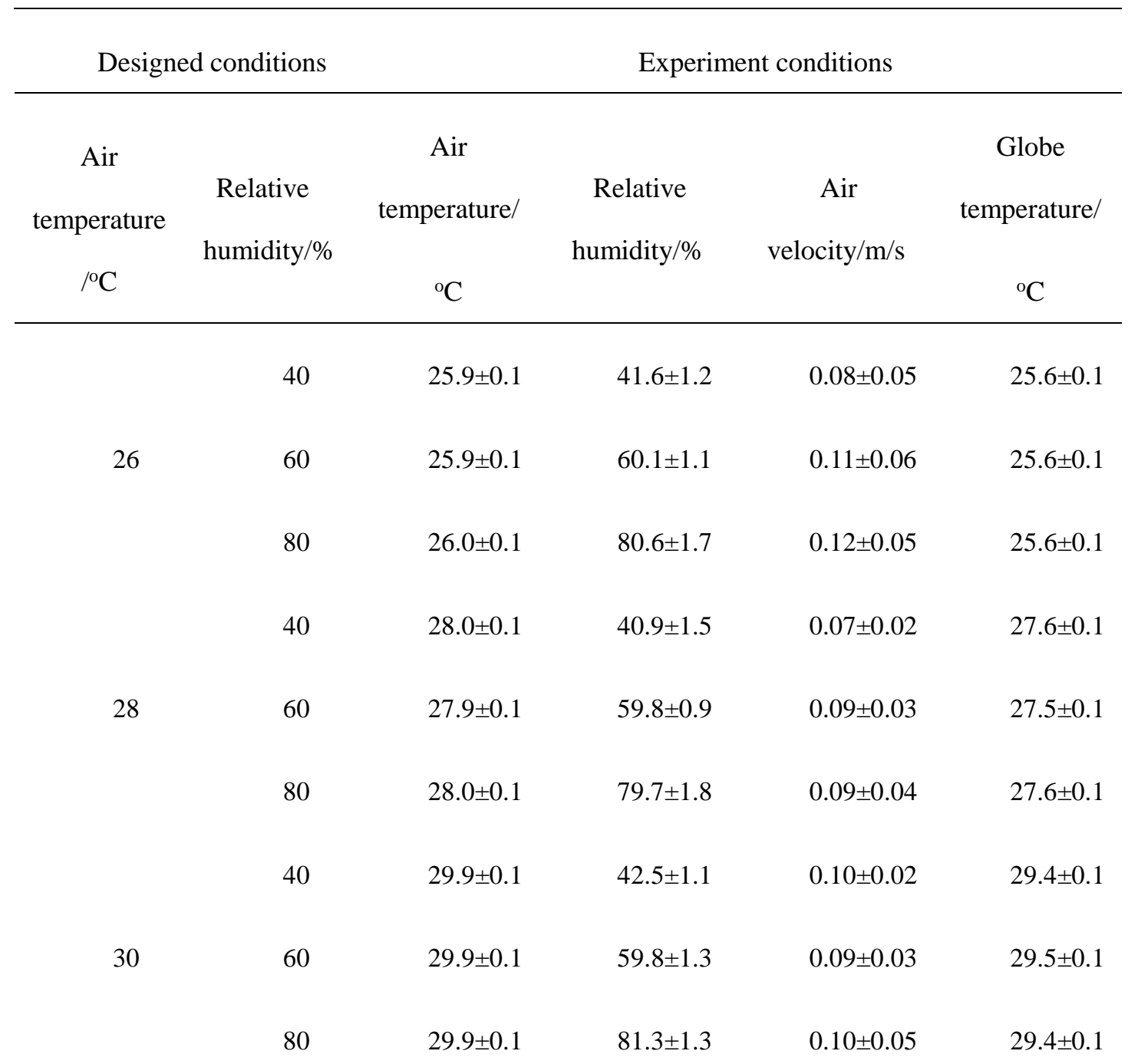


Designed conditions

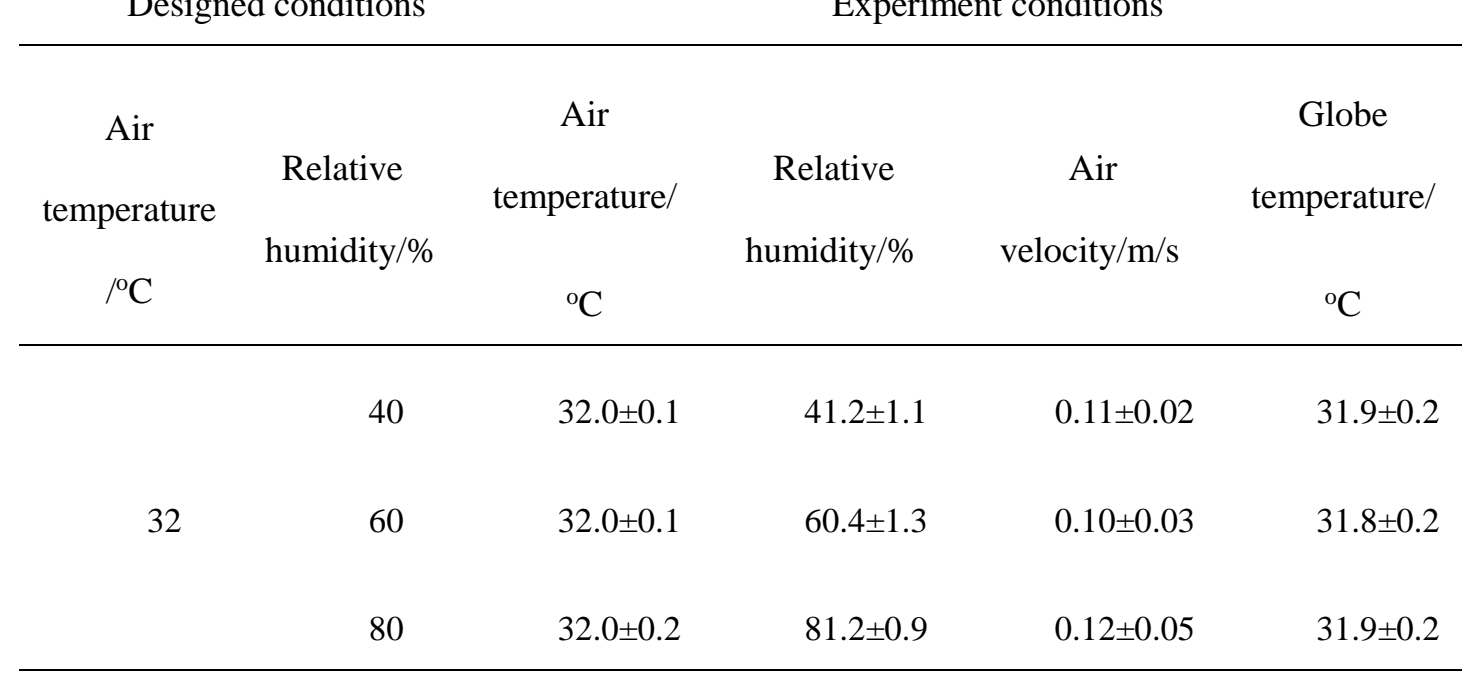

\subsection{Subjects}

As the primary work, a large number of experiments aiming to study the effect of humidity and human adaptation on thermal comfort have been conducted with over 400 subjects from 2008 to 2011 in our climate chamber. Empirical and experimental results (the PMV and subjects' real TSV) verifying the effect of high relative humidity on human thermal perceptions have been discussed extensively by Yang et al.[51]. However, the study did not further quantify the effect of relative humidity based on the results. To fill this gap, this study focuses on the method of quantification of the effect of humidity on thermal sensation. $G^{*}$ Power 3 software, a general stand-alone analysis program for statistical tests which is commonly used in social and behavioral research[52], has been used to calculate the sample size based on the experimental conditions. Through the a priori power analysis in $\mathrm{G}^{*}$ Power 3 , the required experiment sample size is 16 . Therefore, in this study, a subject sample size of 20 was selected to meet this requirement.

All the 20 subjects were college students between 20 and 30 years of age and participated in all the experimental conditions. These subjects were recruited randomly from Chongqing due to its distinct hot-humid climatic characteristics. The subjects had all been living in Chongqing for more than one year and were therefore acclimatized to 
the hot-humid climate conditions in summer. Basic personal information was collected such as gender, age, height $\left(\mathrm{H}_{\mathrm{b}}\right)$ and weight $\left(\mathrm{W}_{\mathrm{b}}\right)$ (see Table 2$)$. Subjects were not allowed to take either strenuous exercise or alcoholic drinks for 24 hours before the experiments. They should have had a good sleep on the day before the experiments to meet the required criteria.

Table 2: Physical characteristics of the subjects (Mean $\pm \mathrm{SD})$

\begin{tabular}{ccccc}
\hline $\begin{array}{c}\text { Gend } \\
\text { er }\end{array}$ & Number & $\begin{array}{c}\text { Age } \\
(\text { years })\end{array}$ & Height $(\mathrm{cm})$ & $\begin{array}{c}\text { Weight } \\
(\mathrm{kg})\end{array}$ \\
\hline Male & 10 & $23.6 \pm 1.3$ & $174.1 \pm 4.7$ & $67.6 \pm 8.8$ \\
Female & 10 & $23.9 \pm 1.1$ & $158.9 \pm 3.6$ & $46.6 \pm 4.2$ \\
Total & 20 & $23.7 \pm 1.2$ & $166.5 \pm 8.7$ & $57.1 \pm 8.9$ \\
\hline
\end{tabular}

\subsection{Experimental procedure}

Each of the 12 experimental conditions (Table 1) lasted for 120 minutes. The procedure is illustrated in Fig. 2. During the first 30min, the subjects were firstly asked to put on the uniform clothes (short-sleeve cotton shirts, shorts, sport socks, slippers with insulation values of approximately 0.32clo[40]) and attach a total of eight thermocouples (TSD202B, BIOPAC, US) one each on the forehead, chest, back, upper arm, lower arm, dorsal hand, thigh and calf on the left side of their body. The data for the skin temperatures $\left(\mathrm{T}_{\mathrm{sk}}\right)$ measured at the eight different parts of the body were logged by a multi-channel physiological-acquisition system (MP150, USA). The mean skin temperatures of subjects were calculated using Gagge's eight-point formula, as shown in Equation (1)[53]. 


$$
\begin{aligned}
\mathrm{MST}= & 0.07 * \mathrm{~T}_{\text {forehead }}+0.175 * \mathrm{~T}_{\text {chest }}+0.175 * \mathrm{~T}_{\text {back }}+0.07 * \mathrm{~T}_{\text {upperarm }} \\
& +0.07 * \mathrm{~T}_{\text {lowerarm }}+0.05 * \mathrm{~T}_{\text {hand }}+0.19 * \mathrm{~T}_{\text {thigh }}+0.2 * \mathrm{~T}_{\text {calf }}
\end{aligned}
$$

Subjects were subsequently required to sit quietly in the adjacent room (temperature: $26^{\circ} \mathrm{C}$ ). After this period, the subjects moved into the climate chamber for a $90 \mathrm{~min}$ exposure. During the experiment, the local skin temperatures were recorded every $2 \mathrm{~s}$, while the environmental parameters and subjects' thermal perceptions were recorded every $10 \mathrm{~min}$, as shown in Fig.2. Subjects were sedentary and allowed to do light activities such as reading and listening to music. According to the recommended value in Table 5.2.1.2 of ASHRAE 55-2013[40], the metabolic rate was approximately estimated by 1 met. To note here, although the metabolic rate would be significantly affected by surroundings such as ambient temperature that increased slightly with increased air temperatures [54], the main purpose of this study focuses on the two variables of air temperature and humidity and the metabolic rate is not involved in and assumed to be equal to 1 met in later analysis and evaluation method building.

$\begin{gathered}\text { Preparation room } \\ 26^{\circ} \mathrm{C} / 30 \mathrm{~min}\end{gathered}$
$\begin{aligned} & \text { Changing clothing } \\ & \text { Attaching thermocouples }\end{aligned}$

Figure 2: Experimental process

\subsection{Questionnaires}

During the experiments, subjects were required to fill in the repeated questionnaires every 10min. The main questions discussed in this study, included subjects' whole and local thermal sensations, humidity sensations and sweating sensations. Thermal sensations were quantified using the ASHRAE 7-point scale[40], as well as the humidity sensations. A 5-point scale based on the degree of sweating at the skin surface 
was designed to evaluate subjects' sweating sensation. A detailed description of the responses to different scales is shown in Table 3.

Table 3: Scales used to measure subjective response to environmental variables

\begin{tabular}{|c|c|c|c|c|c|c|c|c|}
\hline Scale & -3 & -2 & -1 & 0 & 1 & 2 & 3 & 4 \\
\hline $\begin{array}{l}\text { Thermal } \\
\text { sensation }\end{array}$ & Cold & Cool & $\begin{array}{c}\text { Slightly } \\
\text { cool }\end{array}$ & Neutral & $\begin{array}{l}\text { Slightly } \\
\text { warm }\end{array}$ & Warm & hot & \\
\hline $\begin{array}{l}\text { Humidity } \\
\text { sensation }\end{array}$ & $\begin{array}{c}\text { Too } \\
\text { humid }\end{array}$ & Humid & $\begin{array}{l}\text { Slightly } \\
\text { humid }\end{array}$ & Just right & $\begin{array}{c}\text { Slightly } \\
\text { dry }\end{array}$ & Dry & Too dry & \\
\hline $\begin{array}{l}\text { Sweating } \\
\text { sensation }\end{array}$ & & & & $\begin{array}{c}\text { No } \\
\text { sweating, } \\
\text { skin dry }\end{array}$ & $\begin{array}{l}\text { No } \\
\text { sweating, } \\
\text { but skin } \\
\text { sticky }\end{array}$ & $\begin{array}{l}\text { Slightly } \\
\text { sweating, } \\
\text { skin } \\
\text { moist }\end{array}$ & $\begin{array}{l}\text { Sweating, } \\
\text { skin } \\
\text { droplets }\end{array}$ & $\begin{array}{l}\text { Much } \\
\text { sweating, } \\
\text { droplets } \\
\text { falling }\end{array}$ \\
\hline
\end{tabular}

\subsection{Data processing and analysis}

To judge whether the subjects' objective and subjective responses stabilize, the repeated measurement analysis of variance (ANOVA) was conducted to test the differences within the results obtained from repeated measurements in different time intervals. Therefore, subjects' skin temperatures and subjective votes presented in Section 3 are the mean values in steady-state conditions according to the statistical results, shown as mean \pm SD in this paper. The effect of different temperature and relative humidity levels on human thermal responses was also examined using ANOVA and a significance level of 0.05 was adopted. 


\section{Results}

\subsection{Mean skin temperature}

Fig. 3 shows the mean skin temperature (MST) of the 20 subjects in the 12 designed experimental conditions (Table 1). As shown in Fig.3, the MST increases from $33.5^{\circ} \mathrm{C}$ at air temperature of $26^{\circ} \mathrm{C}$, to around $35^{\circ} \mathrm{C}$ at $32^{\circ} \mathrm{C}$. Subjects' maximum MST at $32^{\circ} \mathrm{C}$ is approximately $2{ }^{\circ} \mathrm{C}$ higher than that at $26^{\circ} \mathrm{C}$ when the relative humidity is equal to $80 \%$. The statistical results (ANOVA) show that there is no significant difference in the MST at the three relative humidity levels $(40 \%, 60 \%$ and $80 \%)$ for these four temperature levels $\left(26^{\circ} \mathrm{C}, 28^{\circ} \mathrm{C}, 30^{\circ} \mathrm{C}, 32^{\circ} \mathrm{C}\right)$ respectively $(\mathrm{P}=1.000$ for each temperature condition). The maximum difference of subjects' MST is just $0.28^{\circ} \mathrm{C}$ at $32^{\circ} \mathrm{C}$ between $40 \% \mathrm{RH}$ and $80 \% \mathrm{RH}$, suggesting that under the same temperature conditions the effect of humidity on subjects' MST is slight. However, it is interesting to note in Fig. 3 that when the temperature increases from $28^{\circ} \mathrm{C}$ to $30^{\circ} \mathrm{C}$, the MST at $40 \% \mathrm{RH}$ increases by $0.66^{\circ} \mathrm{C}$ while when the temperature increases from $30^{\circ} \mathrm{C}$ to $32^{\circ} \mathrm{C}$, the MST increases by only $0.33^{\circ} \mathrm{C}$ regardless of the same temperature increment. By contrast, at $80 \% \mathrm{RH}$ condition, the increment of MST reduces slightly from $0.64^{\circ} \mathrm{C}$ to $0.56^{\circ} \mathrm{C}$ (demonstrated in red lines in Fig.3). This is inferred due to the effect of subjects' sweating evaporation, which would be explained by Fig.7. That is to say, in hot environments, especially for the low humidity condition of $40 \%$, the sensible sweating evaporation enhanced effectively and takes more heat from the skin surface to the surroundings, which in turn prevents the increase in the subjects' MST. 


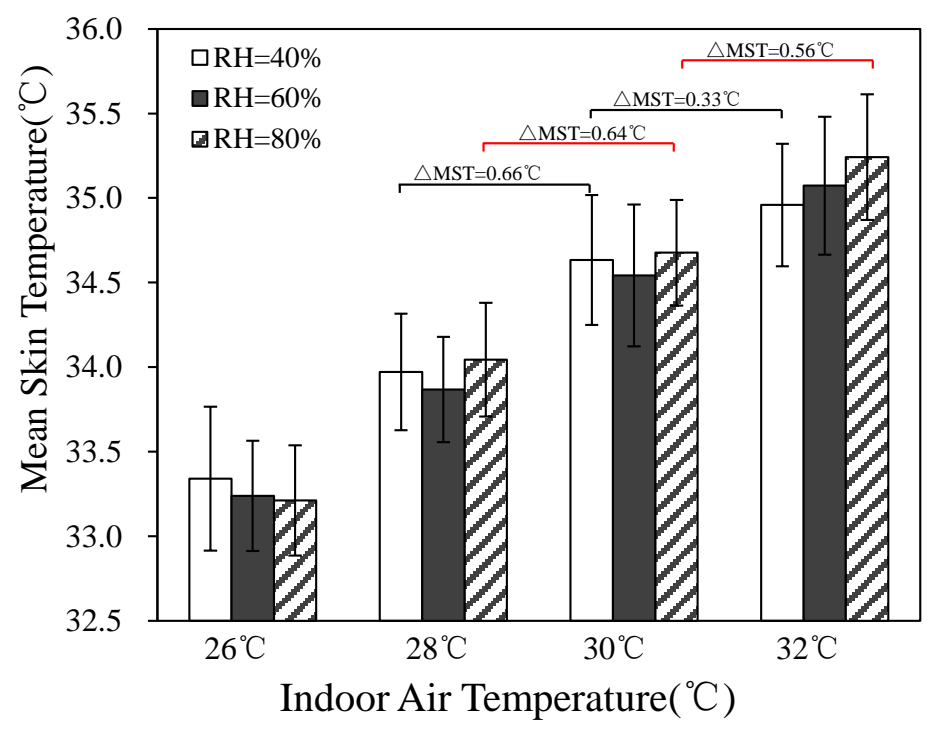

Figure 3: Mean skin temperature in responding to air temperature under different humidity levels.

\subsection{Thermal sensation and its relation to SET}

The average values of subjects' thermal sensation votes (TSV) under different indoor air temperatures and relative humidity levels are shown in Fig. 4. Overall, the subjects' TSVs increase significantly with the increasing temperature, except at the temperature of $26^{\circ} \mathrm{C}$. When the temperature is at $26^{\circ} \mathrm{C}$ in Fig.4, the higher the relative humidity is, the lower (towards cooler) the subjects' TSV is, which suggests that the damp air in neutral environments would aggravate subjects' cool sensation. Moreover, the differences of TSV between $40 \% \mathrm{RH}$ and $60 \% \mathrm{RH}, 40 \% \mathrm{RH}$ and $80 \% \mathrm{RH}, 60 \% \mathrm{RH}$ and $80 \% \mathrm{RH}$ increase at each temperature condition of $28^{\circ} \mathrm{C}, 30^{\circ} \mathrm{C}$, and $32^{\circ} \mathrm{C}$, suggesting the effect of relative humidity on subjects' TSV takes place when the temperature is high. The statistical results show that no significant differences of TSV are observed ( $>0.05$ ) among the three humidity levels when the air temperatures are at $26{ }^{\circ} \mathrm{C}$ and $28{ }^{\circ} \mathrm{C}$. When the temperatures are at $30^{\circ} \mathrm{C}$ and $32^{\circ} \mathrm{C}$, significant differences $(\mathrm{p}<0.05)$ are found between different humidity levels. The higher the temperature and relative humidity are, the greater the difference of TSVs are between two humidity conditions. This indicates that higher air humidity could cause subjects' uncomfortably warmer sensations in the warm and hot environments, which is in agreement with other 
studies $[9,35,36]$.

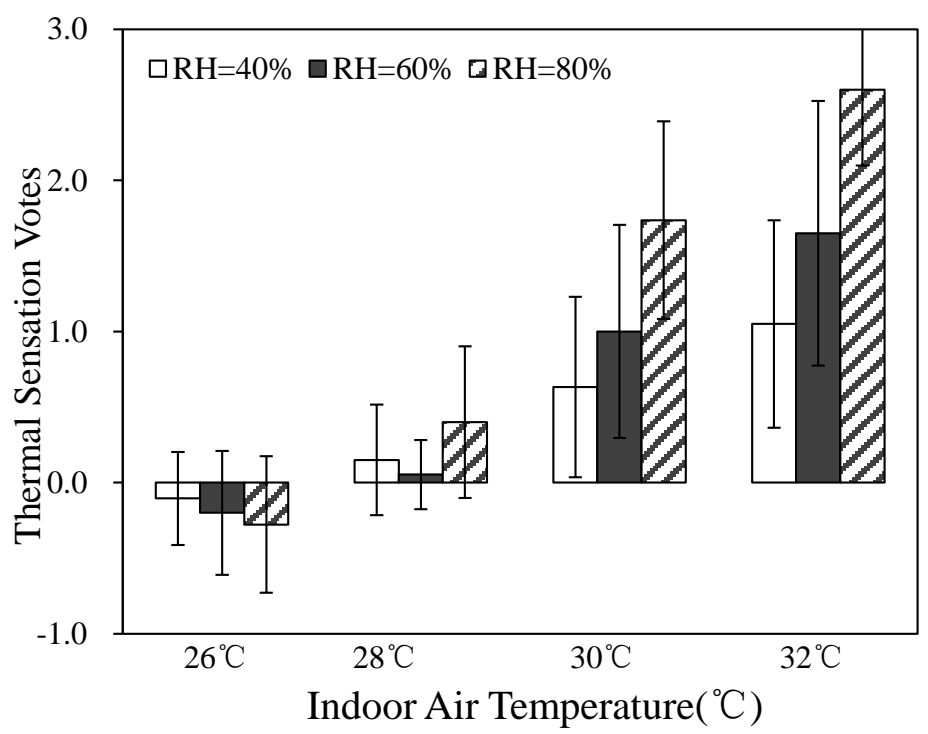

Figure 4: TSV changes with air temperature under different relative humidity levels.

As aforementioned, the PMV index, which is widely used to evaluate moderate thermal environments, does work only under specific conditions (e.g. $\mathrm{t}_{\mathrm{a}}<30^{\circ} \mathrm{C}, \mathrm{Pa}<2700 \mathrm{~Pa}$ ) and thus it is inappropriate to use PMV to evaluate the human thermal sensation in warm environments with high air humidity, especially in hot-humid environments. By contrast, the SET index is deduced by human physiological model and have been confirmed to be related to human thermal sensation in hot-humid environments[35, 55]. Fig. 5 shows the relation between SET and TSV under different temperature and humidity conditions. It is clearly seen that there is a good linear relationship between TSV and SET $\left(\mathrm{R}^{2}=0.96, \mathrm{P}<0.01\right)$. The TSV increased from -0.62 to 2.27 when the SET increased from $23.27^{\circ} \mathrm{C}\left(\mathrm{T}_{\mathrm{a}}=26^{\circ} \mathrm{C}, \mathrm{RH}=40 \%\right)$ to $34.48^{\circ} \mathrm{C}\left(\mathrm{T}_{\mathrm{a}}=32^{\circ} \mathrm{C}, \mathrm{RH}=80 \%\right)$. Since the TSV value of 0 representing neutral thermal environment, the corresponding SET of $24.8^{\circ} \mathrm{C}$ can be calculated. Besides, as the air temperature increased, the air humidity did work and the differences of SET between two relative humidity raised, as well as the differences of TSV. However, despite that the SET index is a comprehensive index that involve the physical and physiological parameters, it cannot reflect the actual long- 
term thermal adaption of occupants to hot-humid thermal environments. As a result, whether the SET can be used to evaluate accurately the effect of air humidity on human thermal sensation are reserved and would be discussed in the later part.

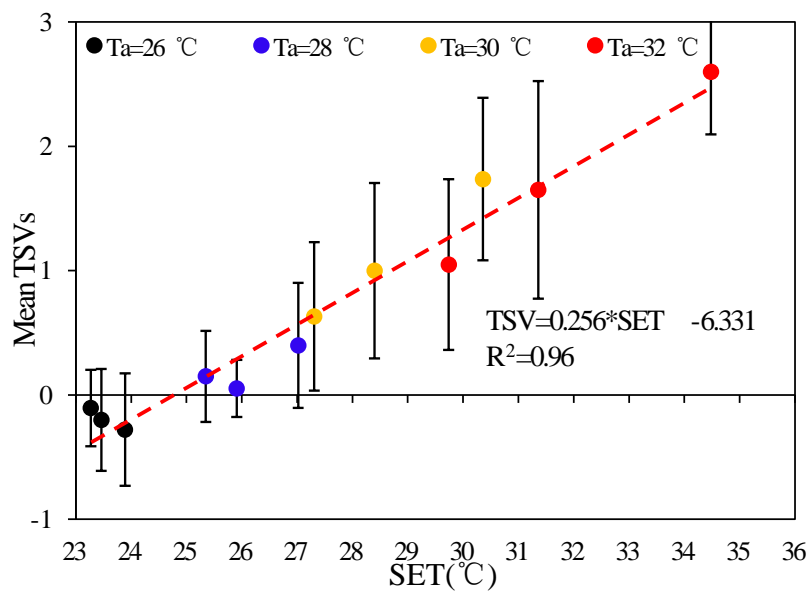

Figure 5: The relationship between SET and TSV under different relative humidity conditions

\subsection{Humidity sensation}

The average values of the humidity sensation vote (HSV) of the subjects under different temperature and relative humidity $(\mathrm{RH})$ conditions are shown in Fig. 6. For the same indoor air temperature, HSV increases with the relative humidity increasing and the difference between two humidity levels is more obvious when the indoor temperature increases to $30^{\circ} \mathrm{C}$ and $32^{\circ} \mathrm{C}$. Through the statistical test (ANOVA) of subjects' TSV at the three humidity levels, there is no significant difference ( $p>0.05)$ of HSV when the temperatures are $26^{\circ} \mathrm{C}$ and $28^{\circ} \mathrm{C}$. When the temperature increases to $30^{\circ} \mathrm{C}$, significant differences of HSV $(\mathrm{p}<0.05)$ are found between $40 \% \mathrm{RH}$ and $80 \% \mathrm{RH}$, and between $60 \% \mathrm{RH}$ and $80 \% \mathrm{RH}$. When the temperature further increases to $32^{\circ} \mathrm{C}$, the HSV shows significant differences $(\mathrm{p}<0.001)$ among the three humidity levels, which is similar to the TSV's change. Additionally, a notable change is circled in Fig. 6: when the temperature increases from $28^{\circ} \mathrm{C}$ to $30^{\circ} \mathrm{C}$ under $80 \% \mathrm{RH}$, the $\mathrm{HSV}$ increases sharply; when the temperature increases from $30^{\circ} \mathrm{C}$ to $32^{\circ} \mathrm{C}$ under $40 \% \mathrm{RH}$, the $\mathrm{HSV}$ decreases rather than increases. This might be explained as the possible effect of subjects' 
sweating. When the $\mathrm{RH}$ is high $(80 \%)$, increasing the temperature from $28^{\circ} \mathrm{C}$ to $30^{\circ} \mathrm{C}$ would have a great effect on a human's subjective humidity sensation. Subjects might begin to sweat at $30^{\circ} \mathrm{C}$ (shown later in Fig.7) and this enhances the humidity sensation; while at $32^{\circ} \mathrm{C}$, subjects would sweat intensively. Under such conditions, the lower humidity enhances the evaporation of perspiration from the skin and reduces the skin wetness, leading to a relatively lower HSV. To sum up, in Fig 6 subjects express less sensitivity to humidity within neutral thermal environments but are more sensitive in warm and hot environments.

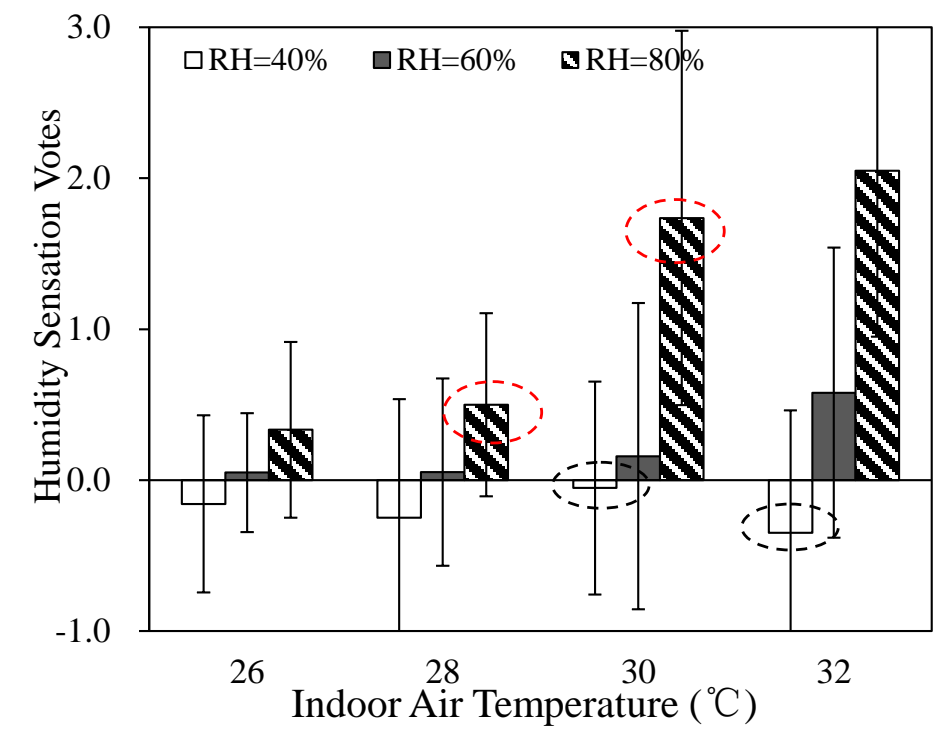

Figure 6: Humidity sensation under different test conditions

\subsection{Sweating sensation}

Sweating evaporation is an efficient way to accelerate the release of heat to surroundings, particularly in hot environments. The mean sweating sensation votes for each part of the subjects' body are shown in Fig.7. The sweating sensations for local parts of the body change similarly to the TSV and $\mathrm{HSV}$ at $26^{\circ} \mathrm{C}$ and $28^{\circ} \mathrm{C}(\mathrm{p}>0.05)$. When the temperature rises to $30^{\circ} \mathrm{C}$, the differences between the sweating sensations at different parts of the body caused by different humidity levels increase, meaning that different parts of a subject's body begin to sweat to different extents. In this case, the 
relative humidity begins to affect subjects' sweating regulation. As the temperature rises to $32^{\circ} \mathrm{C}$, subjects' sweating sensations continuously rise and the effects of relative humidity on different parts of the body are more significant, reflected by the significant differences in the sweating sensation for different parts of the body. For example, the difference between $40 \% \mathrm{RH}$ and $80 \% \mathrm{RH}$ is 2.1 for the head while the difference is 1 for the feet. This suggests that a high relative humidity would have a bigger effect on the head than on the feet. The statistical analysis shows significant differences in sweating sensation votes between $40 \% \mathrm{RH}$ and $80 \% \mathrm{RH}$ and between $60 \% \mathrm{RH}$ and $80 \% \mathrm{RH}$ $(\mathrm{p}<0.001)$ when the temperature is $30^{\circ} \mathrm{C}$. At $32^{\circ} \mathrm{C}$, significant differences are noted for all the three different humidity conditions. The results illustrate that when the subjects begin to sweat with increased temperatures, the effect of humidity on the sweating sensation appears and deteriorate the subjects' sweating sensation.
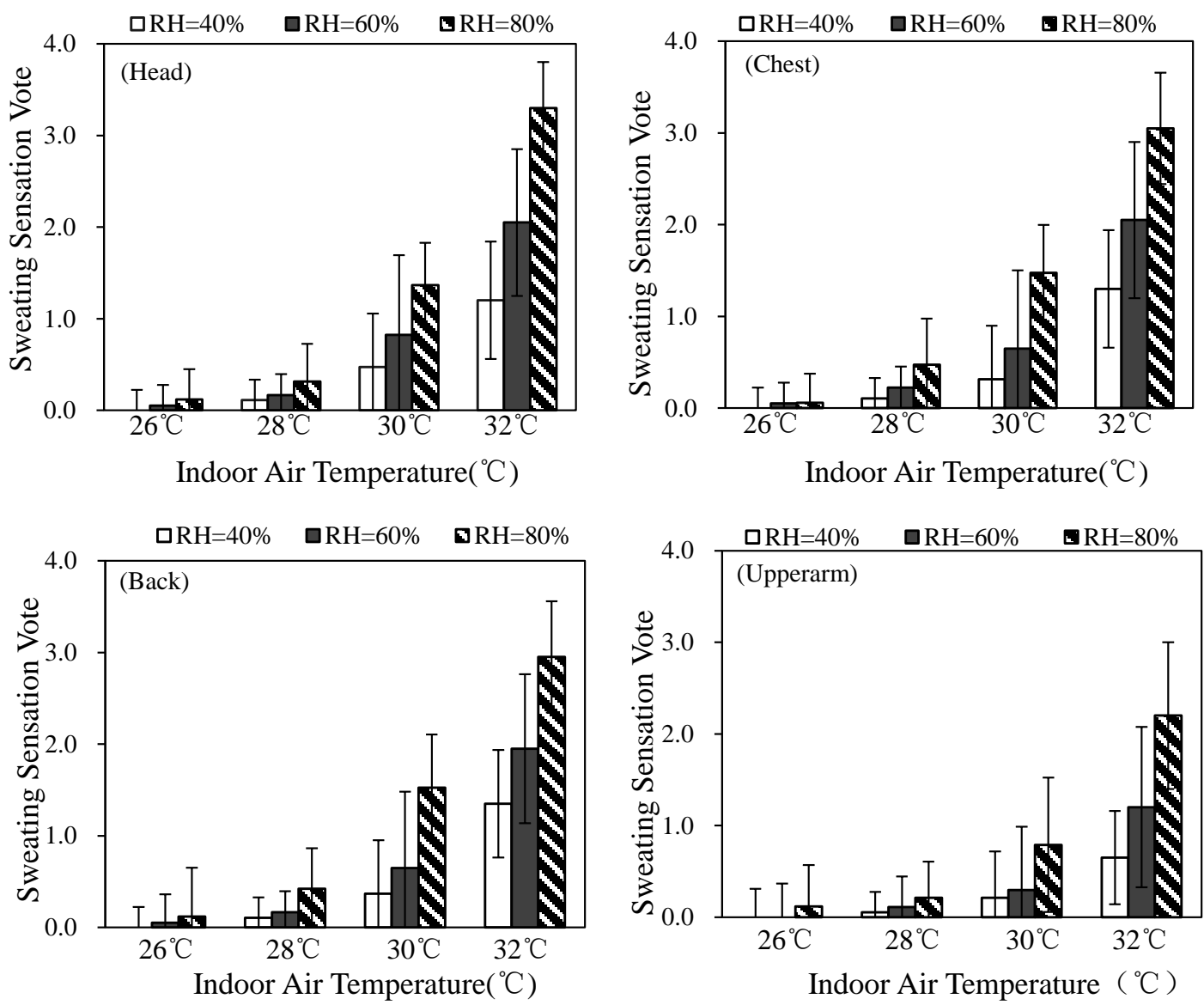

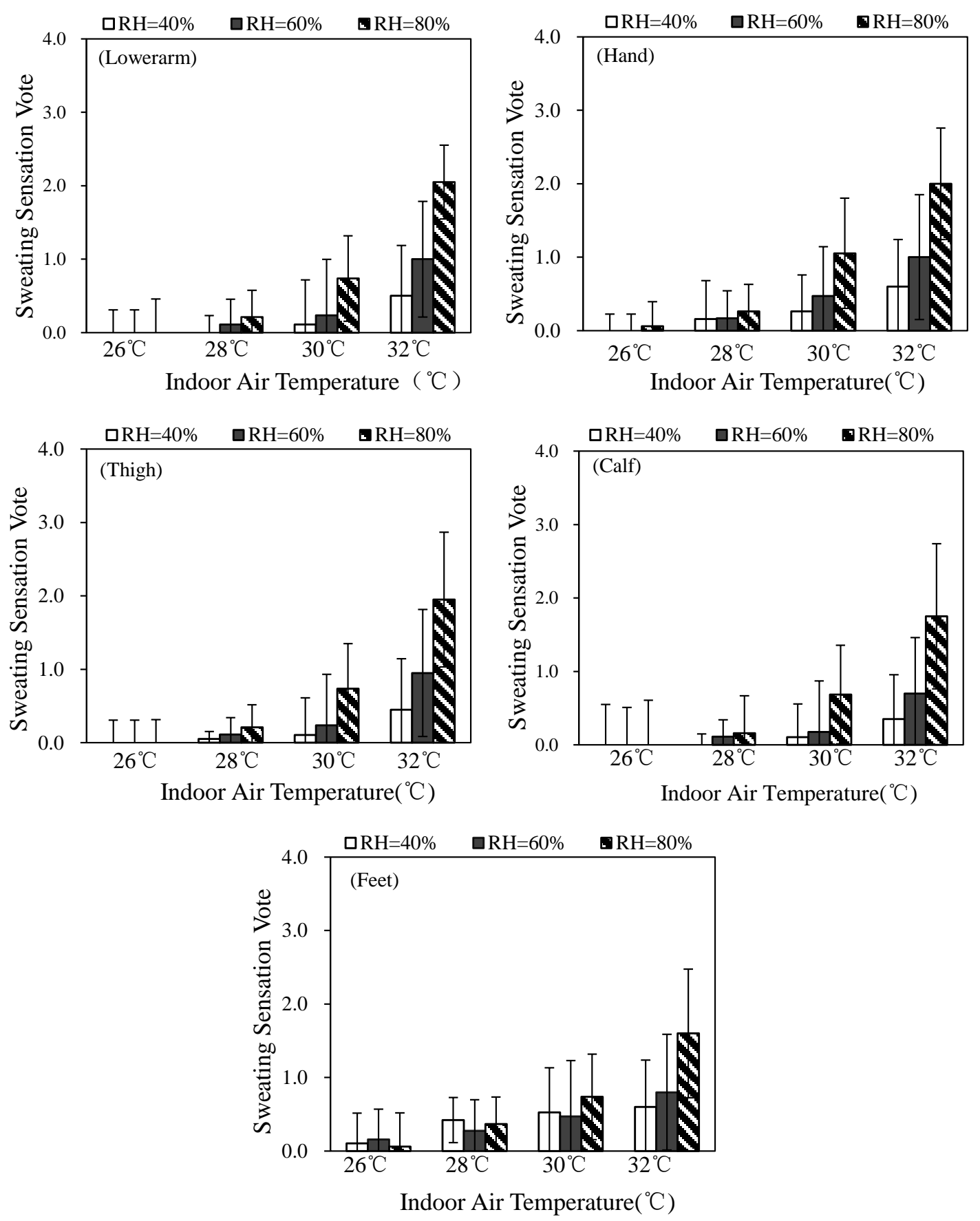

Figure 7: Sweating sensation vote to different air temperatures under different humidity levels

\subsection{Correction of the predicted deviation in SET caused by air humidity}

\subsubsection{SET and the thermal comfort temperature $T_{c}$}

Griffiths[47] proposed a method (the Griffiths method, shown in Equation (2)) to calculate the thermal comfort temperature $T_{c}$ (equivalent to neutral temperature). 
The author proposed a simple standard regression coefficient $\mathrm{G}$, which was defined as the "Griffiths constant, $\mathrm{K}^{-1 "}$ (it is used as ${ }^{\circ} \mathrm{C}^{-1}$ in this paper) to express the linear relationship between human thermal sensation and operative temperature.

$$
C-0=G\left(T_{o p}-T_{c}\right)
$$

Equation (2) can be simplified as follows:

$$
T_{c}=T_{o p}-Q \quad
$$

Where $T_{c}$ is the comfort temperature, ${ }^{\circ} \mathrm{C} ; T_{o p}$ is the operative temperature, ${ }^{\circ} \mathrm{C}$;

$\mathrm{C}$ is the real thermal sensation vote (ASHRAE 7-point scale);

$\mathrm{G}$ is the Griffiths constant, ${ }^{\circ} \mathrm{C}^{-1}$.

According to Griffith[47], the Griffiths method was based on the field study of thermal comfort and the G value was mainly deduced via the regression analysis of occupants' thermal sensation in a wide range of environmental temperatures and air humidity. Therefore, the key point of this method to a great degree depends on the determination of $\mathrm{G}$ value appropriately. Humphreys et al. [56]obtained the maximum regression coefficient of $0.4^{\circ} \mathrm{C}^{-1}$ when the standard deviation of temperature was about $1{ }^{\circ} \mathrm{C}$ based on the reanalysis of several thermal comfort databases from other researchers (e.g. de Dear et al.[57]; Nicol et al.[58]; McCartney and Nicol[59]). Considering error in the predict variable and some adaptation error at the maximum of the curve, Nicol and Humphreys [60]pointed out that the $\mathrm{G}$ constant had better be greater than 0.4 to be safe and recommended an appropriate $\mathrm{G}$ value of $0.5^{\circ} \mathrm{C}^{-1}$. This means the corresponding thermal sensation vote based on the ASHRAE 7-point scale will change by 0.5 if the indoor operative temperature changes by $2^{\circ} \mathrm{C}$. The value is also adopted in this study.

Based on the $\mathrm{G}$ constant (0.5), the thermal sensation vote $\mathrm{C}$ and the operative temperature $T_{o p}$, the corresponding comfort temperature $T_{c}$ then can be calculated. For the same operative temperatures, the difference of thermal comfort temperatures $T_{c}$ arising under two different humidity levels can actually reflect the effect of humidity on thermal sensation. Accordingly, here we denote the thermal comfort temperature 
difference between two different relative humidity levels as $\delta T_{c-R H}$ to represent the actual humidity effect on thermal sensation. Similarly, the difference of the SET under two different relative humidity levels can be calculated based on Gagge's model[43], namely $\delta S E T_{R H}$, which is used to represent the theoretical effect of humidity on thermal sensation. In particular, the SET is just an equivalent temperature metric, which reflects comprehensively the effect of environmental variables on human physiological responses and subjective thermal perception indirectly. In theory, the SET is applicable to a variety of thermal environments. .

When the air temperature is constant, $T_{c}$ decreases as the relative humidity increases, while SET increases as the relative humidity increases. Then $\delta T_{c^{-} R H}$ and $\delta T_{c^{-}}$ $R H$ can be given by Equations (4) and (5).

$$
\begin{aligned}
& \delta T_{c^{-} R H}=T_{c 1}-T_{c 2} \\
& \delta S E T_{R H}=S E T_{2}-S E T_{1}
\end{aligned}
$$

where subscripts 1 and 2 represent different relative humidity conditions. In this study, we define $\mathrm{RH}_{2}>\mathrm{RH}_{1}$, and denote $\mathrm{RH}_{1}$ as the minimum relative humidity level of $40 \%$ in our experiments. Thus, $\mathrm{RH}_{2}=60 \%$ and $\mathrm{RH}_{3}=80 \%$ can be similarly defined.

The $\delta T_{c^{-} R H}$ and the $\delta S E T_{R H}$ can then be calculated based on the data collected from the experiments and be plotted in Fig.8. The dots represent the differences of $T_{c^{-} R H}$ and $S E T_{R H}$ between $40 \% \mathrm{RH}$ and $60 \% \mathrm{RH}$ under all temperature conditions; while the triangles represent the differences of $T_{c^{-} R H}$ and $S E T_{R H}$ between $40 \% \mathrm{RH}$ and $80 \% \mathrm{RH}$. From Fig. 8, there is a linear relationship between $\delta T_{c-R H}$ and $\delta S E T_{R H}$. The regression equations are as follows:

When $\delta \mathrm{RH}=20 \%$ (The difference between $\mathrm{RH}_{2}$ and $\mathrm{RH}_{1}$ ),

$$
\delta T_{c-R H}=1.03 \delta S E T_{R H}-0.48 \quad R^{2}=0.95
$$

When $\delta \mathrm{RH}=40 \%$ (The difference between $\mathrm{RH}_{3}$ and $\mathrm{RH}_{1}$ ),

$$
\delta T_{c-R H}=0.84 \delta S E T_{R H}-0.79 \quad R^{2}=0.94
$$




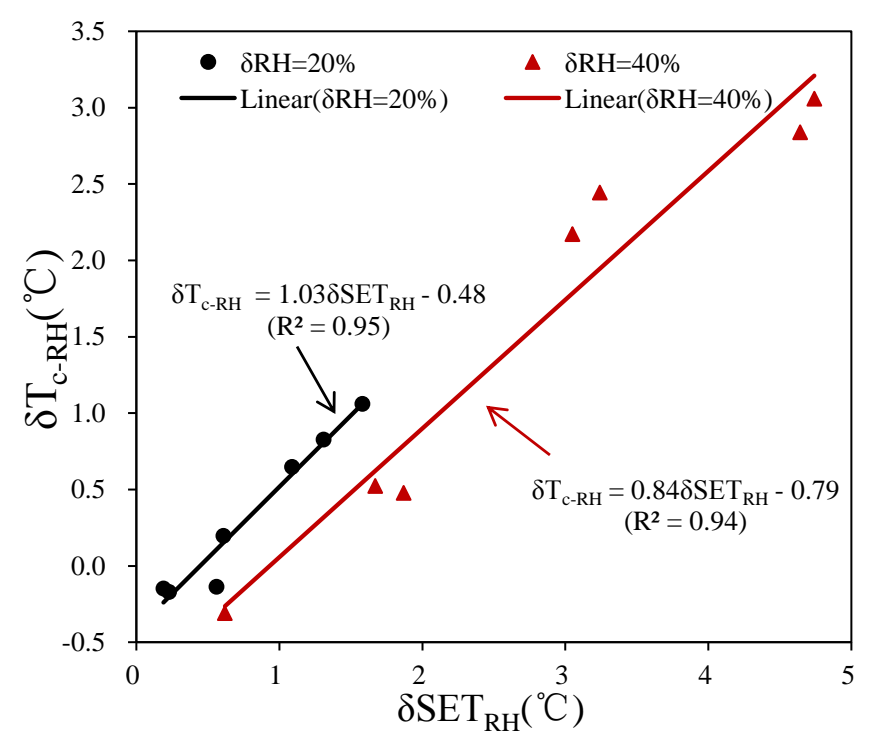

Figure 8: Relation between $\delta S E T_{R H} a$ nd $\delta T_{c-R H}$ with the $\delta R H$ values of $20 \%$ and $40 \%$

\subsubsection{The modified $S E T_{R H}$ and the correction coefficient $e_{R H}$}

From the abovementioned, $\delta T_{c-R H}$ is drawn from occupants' real thermal sensation empirically based on field studies where the long-term thermal adaptation is embodied, whereas the $\delta S E T_{R H}$ depends on the theoretical heat balance of the human body that occupants' thermal adaptation cannot be reflected. Therefore, the deviation caused by two relative humidity level between the $\delta \mathrm{T}_{\mathrm{c}-\mathrm{RH}}$ and the $\delta \mathrm{SET}_{\mathrm{RH}}$ indicates that the predicted SET neglects the subjects' thermal adaptation. However, from Equations (6) and (7) the theoretical $\delta S E T_{R H}$ is linearly related to the real $\delta T_{c^{-} R H}$. We therefore denote a correction coefficient " $e_{R H}$ ", called the humidity correction coefficient, to correlate the relationship between $\delta T c_{-R H}$ and $\delta S E T_{R H}$, as shown in Equation (8):

$$
\delta T_{\mathrm{c}-R H}=e_{R H} * \delta S E T_{R H}
$$

Then, Equations (6) and (7) can be transformed using the correction coefficient " $e_{R H}$ ". When $\delta \mathrm{RH}=20 \%$, 


$$
\delta T_{\mathrm{c}-\mathrm{RH}}=e_{R H} * \delta S E T_{R H}=1.03 \delta S E T_{R H}-0.48=\left(1.03-\frac{0.48}{\delta S E T_{R H}}\right) * \delta S E T_{R H}
$$

In this case, the correction coefficient can be expressed as follows:

$$
e_{R H}=1.03-\frac{0.48}{\delta S E T_{R H}}
$$

Similarly, when $\delta \mathrm{RH}=40 \%$,

$$
\begin{aligned}
\delta T_{c-R H} & =e_{R H} * \delta S E T_{R H}=0.84 \delta S E T_{R H}-0.79=\left(0.84-\frac{0.79}{\delta S E T_{R H}}\right) * \delta S E T_{R H} \\
e_{R H} & =0.84-\frac{0.79}{\delta S E T_{R H}}
\end{aligned}
$$

\subsubsection{The acceptable air temperature-humidity zones}

Based on the method above, we define $T_{\text {air }}$ ' as the equivalent indoor air temperature when the thermal sensation is equal to that in the environment with $T_{\text {air }}$ and $\mathrm{RH}=40 \%$. If $\mathrm{RH}=40 \%, T_{\text {air }}{ }^{\prime}=T_{\text {air }}$. As the relative humidity increases, thermal sensation increases and $T_{c-R H}$ decreases. If we would like to maintain the same thermal sensation in the environment under conditions of higher humidity, the air temperature should decrease when the other parameters are constant. Moreover, the value $\delta T_{c}$ is equal to the difference between $T_{\text {air }}$ ' and $T_{\text {air }}$. Then we have the following equation (13).

$$
\mathrm{T}_{\text {air }}^{\prime}-\mathrm{T}_{\text {air }}=\delta \mathrm{T}_{\mathrm{c}-\mathrm{RH}}=\mathrm{e}_{\mathrm{RH}} * \delta \mathrm{SET}_{\mathrm{RH}}
$$

According to Equations (10), (12) and (13), and the given conditions set up in the experiments, we calculated $\delta S E T_{R H}$ under different temperature and relative humidity levels and the modified $e_{R H} \delta S E T_{R H}$ values, as shown in Table 4.It is noted that, though the clothing insulation is 0.32 clo in this study, the modification method presented above does not involve the clothing insulation factor and thus it is appropriate to apply the method to calculate the equivalent air temperatures with a clothing insulation of $0.5 \mathrm{clo}$ (standard summer clothing in ASHRAE 55[40]). Both two series of equivalent indoor air temperatures are shown in Table 4. 
Table 4: The acceptable temperatures using the modified $e_{R H} \delta S E T_{R H}$ model

\begin{tabular}{|c|c|c|c|c|c|c|c|c|c|}
\hline & \multicolumn{2}{|l|}{ Index } & \multicolumn{2}{|l|}{$\mathrm{SET} /{ }^{\circ} \mathrm{C}$} & \multicolumn{2}{|c|}{$e \delta S E T_{R H} /{ }^{\circ} \mathrm{C}$} & \multicolumn{3}{|c|}{$T_{\text {air }}{ }^{\prime \circ} \mathrm{C}$} \\
\hline & $\mathrm{T}_{\mathrm{a}}$ & $\mathrm{RH}=40$ & $\mathrm{RH}=60$ & $\mathrm{RH}=80$ & $\delta \mathrm{RH}=20$ & $\delta \mathrm{RH}=40$ & $\mathrm{RH}=40$ & $\mathrm{RH}=60$ & $\mathrm{RH}=80$ \\
\hline \multirow{5}{*}{$\begin{array}{c}0.32 \text { clo } \\
0.1 \mathrm{~m} / \mathrm{s}\end{array}$} & 28 & 25.68 & 26.4 & 27.55 & 0.26 & 0.78 & 28 & 27.74 & 27.22 \\
\hline & 29 & 26.71 & 27.66 & 29.18 & 0.50 & 1.28 & 29 & 28.50 & 27.72 \\
\hline & 30 & 27.73 & 28.93 & 30.85 & 0.76 & 1.83 & 30 & 29.24 & 28.17 \\
\hline & 31 & 28.76 & 30.21 & 32.57 & 1.01 & 2.41 & 31 & 29.99 & 28.59 \\
\hline & 32 & 29.78 & 31.5 & 34.33 & 1.29 & 3.03 & 32 & 30.71 & 28.97 \\
\hline \multirow{5}{*}{$\begin{array}{l}0.5 \mathrm{clo} \\
0.1 \mathrm{~m} / \mathrm{s}\end{array}$} & 28 & 26.86 & 27.76 & 29.15 & 0.45 & 1.13 & 28 & 27.55 & 26.87 \\
\hline & 29 & 27.85 & 28.97 & 30.70 & 0.67 & 1.60 & 29 & 28.33 & 27.40 \\
\hline & 30 & 28.83 & 30.19 & 32.29 & 0.92 & 2.12 & 30 & 29.08 & 27.88 \\
\hline & 31 & 29.81 & 31.41 & 33.91 & 1.17 & 2.65 & 31 & 29.83 & 28.35 \\
\hline & 32 & 30.78 & 32.64 & 35.56 & 1.44 & 3.23 & 32 & 30.56 & 28.77 \\
\hline
\end{tabular}

As discussed above, the effect of air humidity on human thermal comfort occurs with high air temperature and in such case occupants' thermal adaptation to hot-humid conditions would express. Based on the 7-scale metrics of thermal sensation in this study, the subjects' TSV were both lower 0.5 when the temperature was $28^{\circ} \mathrm{C}$ for three humidity levels, meaning the effect of air humidity could be exclusively considered. In such case, the air temperature of $28^{\circ} \mathrm{C}$ was taken as the lower limit to judge whether the effect of increasing air humidity should be considered on the human acceptable temperatures. On the other hand, when the temperatures were at $30^{\circ} \mathrm{C}$ and $32^{\circ} \mathrm{C}$, the subjects' TSV was under 0.5 only under the condition of $30^{\circ} \mathrm{C} / 40 \% \mathrm{RH}$. It suggests the 
air temperature of $30^{\circ} \mathrm{C}$ was the upper limit for subjects and thus it was defined as the upper limit of acceptable air temperature. In fact, study from Yao et al. [61]verified there was a higher comfort range of occupants in the hottest period in summer (e.g. The comfort temperature is $26.3{ }^{\circ} \mathrm{C}$ in July and therefore the comfort range will be between 22.8 and $29.8{ }^{\circ} \mathrm{C}$ with low standard in naturally ventilated buildings), which is in line with study. Accordingly, in Fig.9, the paper presented an example which shows the indoor acceptable air temperature ranges under different relative humidity levels with the correction to the SET model based on Table 4. In Fig. 9, the area enclosed by two green lines is drawn with the clothing insulation of 0.32clo based on this study. Besides, based on the proposed modified method, the adaptation factor $e_{R H}$ mainly reflects the occupants' long-term physiological adaptation to hot-humid thermal environments in daily life, and the difference caused by two humidity levels is less related to the clothing differences. Therefore it is appropriate to using the method with the standard summer clothing (0.5clo) recommended in ASHRAE 55[40] and the acceptable temperature zone can be drawn through equivalent calculation, as shown by two black lines in Fig.9. It is clearly seen that both the acceptable temperature limits decreases when the humidity increases under two clothing insulation levels. However, the lower clothing insulation of 0.32 clo contributes to the higher acceptable air temperature limits, demonstrating that clothing regulation is also a major factor that affects human thermal comfort in hot environments. 


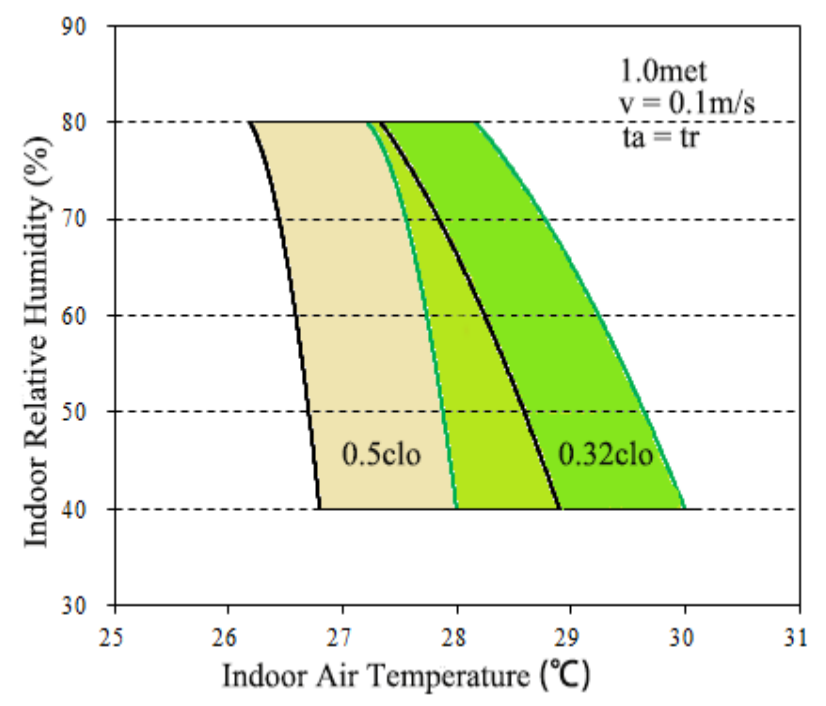

Figure 9: The acceptable thermal comfort zone based on the modified SET model with the humidity correction coefficient

It should be noted that, as mentioned above, the metabolic rate of 1.0 met, the air velocity of $0.1 \mathrm{~m} / \mathrm{s}$ and $t_{\mathrm{a}}=\mathrm{t}_{\mathrm{r}}$ has been used as prerequisite during the calculation. This condition could be argued about the impacts on the obtained acceptable temperaturehumidity zone in Fig.9. However the proposed modification method is based on the differences of $\mathrm{T}_{\text {comf }}$ and SET between two different levels ( $\delta \mathrm{T}_{\text {comf }}$ and $\left.\delta \mathrm{SET}\right)$, so the fixed variables of air velocity and met rate as well as the assumption of ta=tr is acceptable. The result presents an example to draw the acceptable temperaturehumidity zone with the fixed variables.

\section{Discussion}

\subsection{The coupled effect of temperature and relative humidity on MST and TSV}

The mean skin temperature (MST) is an important physiological parameter reflecting human responses to cold or warm stimuli. Several researchers have found that there is a linear relationship between mean skin temperature and human thermal sensation in certain comfort ranges [62-64]so that it can be an essential physiological index to predict human thermal comfort. We also presented the average values of subjects' TSV 
against MST at steady-state under different temperature and relative humidity levels, as shown in Fig.10. The four colors in Fig. 10 represent the four indoor air temperature levels in this study (black: $26^{\circ} \mathrm{C}$, blue: $28^{\circ} \mathrm{C}$, yellow: $30^{\circ} \mathrm{C}$, red: $32^{\circ} \mathrm{C}$ ) and the three symbols represent the three relative humidity levels (square: $40 \% \mathrm{RH}$, circle: $60 \% \mathrm{RH}$, triangle: $80 \% \mathrm{RH})$. From the figure, we can see that the MST and TSV increase significantly with the rising air temperatures. When the air temperature is under $28^{\circ} \mathrm{C}$ and the MST is lower than $34^{\circ} \mathrm{C}$, there is a linear relationship $\left(\mathrm{R}^{2}=0.87\right)$ between MST and TSV, which agrees with other studies[62-64]. However, when the temperature is above $30^{\circ} \mathrm{C}$, the correlation between the TSV and the MST dispersed. The TSV increases sharply with the rising RH from $40 \%$ to $80 \%$, while the MST shows only a slight increase, suggesting the effect of higher relative humidity is more significant on human thermal sensation. For example, when the relative humidity increases from $40 \%$ to $80 \%$, the increments of the TSV are respectively $1.1\left(\right.$ at $\left.30^{\circ} \mathrm{C}\right)$ and $1.6\left(\right.$ at $\left.32^{\circ} \mathrm{C}\right)$ while the increments of the MST are only $0.14^{\circ} \mathrm{C}\left(30^{\circ} \mathrm{C}\right)$ and $0.28^{\circ} \mathrm{C}\left(32^{\circ} \mathrm{C}\right)$. These changes indicate that MST fails to predict TSV in hot-humid conditions. In hot environments, although the increasing temperature would increase subjects' skin temperature due to convection heat loss, the sweating regulation would play the dominant role gradually, which in turn restrain the increase of skin temperatures. But on the other hand, the increasing air humidity would increase the water vapor pressure and prevent the perspiration on the skin surface from evaporating effectively, leading to the inconsistent change of MST and TSV. 


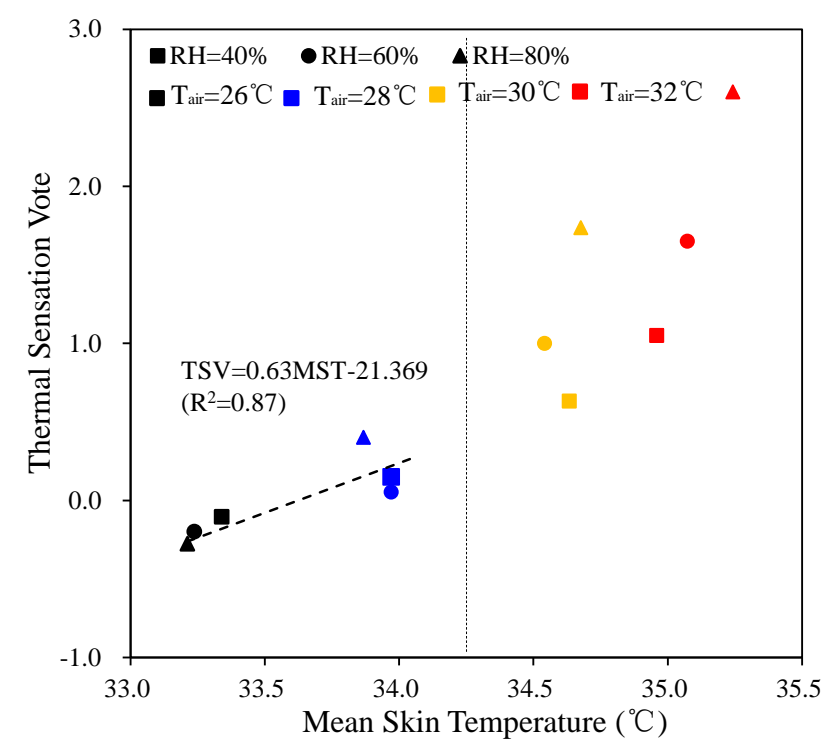

Figure 10: Thermal sensation versus mean skin temperature for different experimental conditions

Besides, it is known that in warm and hot environments human thermoregulation works to a limited extent. In such case, sweating regulation of the human body would be enhanced and the latent heat loss through evaporation will increase, which would in turn affect the thermoregulatory responses. In this study, the changing trend of the MST at the condition of $32^{\circ} \mathrm{C} / 40 \% \mathrm{RH}$ differs to that of $32^{\circ} \mathrm{C} / 80 \% \mathrm{RH}$ (see Fig.3). Due to sweating and higher skin wetness, the water vapor pressure difference under the condition of $32^{\circ} \mathrm{C} / 40 \% \mathrm{RH}$ is larger so that the perspiration could effectively evaporate and thus enhance the heat loss from skin surface. This alleviates significantly the upward trend of skin temperature in Fig.3. Overall, this verifies that the effect of air humidity, coupled with air temperature, is complicated on human thermoregulation and thermal perception.

\subsection{Acceptable temperatures due to thermal adaptation}

As argued before, the comfort zone in the present standard[40] defines a moderate temperature and humidity range. However, its applicability in hot environments is challenged. Though a large number of studies on human thermal adaptation provide a 
wide range of thermal comfort zone through the adaptive models[3, 44, 45, 56, 60], these studies concentrated on the effect of temperatures rather than humidity. Studies from laboratory experiments have further verified and improved the understanding of human thermal adaptation to temperature[65-67] but have contributed little to the understanding of humidity, especially in high relative humidity environments.

Our previous study[51] had argued that the PMV overestimated the actual human thermal sensation under high humidity conditions due to people's long-term thermal adaptation, but the appropriate acceptable temperatures caused by adaptation to high humidity were not revealed. Therefore, this research focuses on the development of an empirical method to quantify the effect of human thermal adaptation to high humidity and works out the acceptable temperature-humidity zone by denoting a correction coefficient $e_{R H}$ (Fig.9). Based on the experimental conditions, here we plotted the acceptable temperature ranges according to the SET model and the modified method in Fig.11 with the same clothing insulation of 0.32 clo. The square and triangle symbols are temperature values under three relative humidity levels $(40 \%, 60 \%, 80 \%)$, where the square ones are calculated by the SET model and the triangle ones are calculated by the modified method. Accordingly, the two solid lines are the lower and upper acceptable temperature limits using the SET model and the two dotted lines are the modified ones considering subjects' thermal adaptation. The deviation of acceptable temperatures under different relative humidity levels with and without considering human thermal adaptation is directly seen from Fig.11. Please note, the human behavioral adaptation, like clothing regulation and air velocity, has been input parameters and reflected during the SET calculation. Accordingly, in Fig.11 the deviation of the acceptable air temperatures between the SET model and the modified ones mainly result from the long-term physiological acclimatization and psychological expectation of occupants in daily life, which fails to be reflected in the SET model. That is to say, on the one hand, the occupants living in hot-humid environments for long time have higher tolerance to temperature and humidity[3, 51, 64], and thus lower their psychological expectation. This lead to the relative high acceptability of temperatures 
for occupants under high relative humidity[51]. On the other hand, the long-term exposure to hot-humid conditions would cause the differences physiologically, like sweating regulation, heat dissipation, etc., which could be reflected by our previous study on the thermoregulation model of human body[68] considering individual differences. Therefore, to the same hot-humid stimuli, the thermoregulation enhances and the corresponding physiological responses are not much stranger, which would in turn affects the subjective thermal perceptions.

As a result, the SET model overestimates the effect of humidity on human acceptable temperatures in warm/hot environments. For the modified model with the humidity correction, the upper acceptable temperature increases at the same humidity level. Besides, with the relative humidity increasing, the deviation of the acceptable temperatures between the SET model and the modified method is greater. For instance, under the relative humidity level of $80 \%$, the maximum difference between the upper acceptable limits before and after thermal adaptation modification is up to $1.29^{\circ} \mathrm{C}$, manifesting the improved tolerance and acceptability of occupants to hot and humid thermal environments.

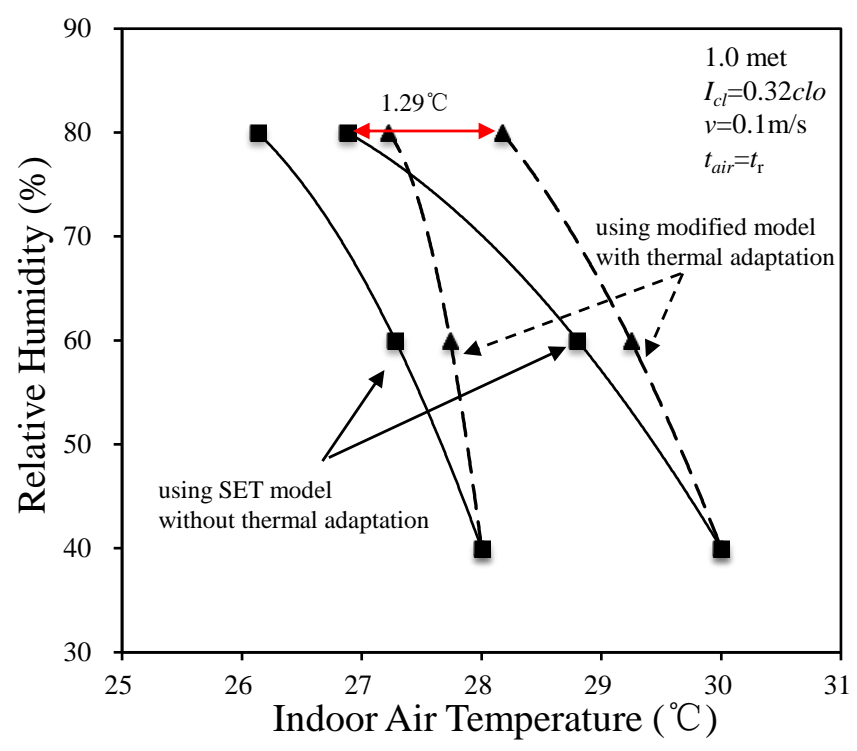

Figure 11: Comparison of air temperatures with and without thermal adaptation modification 


\subsection{The application of the modification method and its limitations}

In ASHRAE 55[40], the upper temperature and humidity limits of the comfort zone in summer can be extended upwards if the air speed is over $0.2 \mathrm{~m} / \mathrm{s}$ (up to $1.2 \mathrm{~m} / \mathrm{s}$ ). In this study, when subjects' thermal adaptations to temperature and humidity in hot and humid conditions are considered, the acceptable temperature limits also increased (Fig. 11), even though the air movement is not accessible. In this case, it can be regarded as a supplement and extension to the temperature and humidity boundaries in ASHRAE 55. However, though the acceptable temperature-humidity zone in Fig.9 is drawn according to experimental results, and obtained with several prerequisites such as the assumed metabolic rate of $1.0 \mathrm{met}$, the lower air velocity $(<0.1 \mathrm{~m} / \mathrm{s})$, the equal radiant temperature $\left(\mathrm{T}_{\mathrm{r}}=\mathrm{T}_{\mathrm{a}}\right)$ and the light clothing insulation of $0.32 \mathrm{clo}$, the aim of this study is to provide a method to evaluate the human adaption to air humidity and its effect on acceptable air temperature quantitatively. The method is tenable, especially to evaluate occupants' thermal comfort in free-running buildings, even though these prerequisites change.

It must be said, the findings in this study of increasing acceptable air temperatures due to thermal adaption are mainly based on human thermal comfort, but the air humidity and the health outcomes are worthy of consideration. With increasing air humidity occupants would feel the inhaled air to be much warmer, more stuffy, and less acceptable[69]. Therefore, Toftum[69] concluded that the upper limit for indoor air humidity should rather be based on the effect of high humidity on perceived air quality and on the growth of fungi and microorganisms. In this study, the investigation of subjects' perceived air quality during the experiments is exclusively considered and is not embedded in the modification method here. Accordingly, more attention should be paid to the air quality under hot-humid conditions when designing the indoor thermal environments properly.

A large number of cross-sectional and longitudinal studies have verified that long-term high air humidity exposure would increase cardiovascular and respiratory disease 
admissions[70], and the risk of pulmonary and respiratory disease[71, 72], indirectly suggesting that the air humidity has a great effect on human health. In view of this point, humidity control is worthy of consideration. Technologies of independent temperature and humidity control are becoming good methods to solve this problem [73] and the low economic cost [74]may contribute to its application possibilities in office or residential buildings widely.

Overall, the effect of air humidity on human thermal perception and health is complex. Even though this paper proposes the modification method and quantifies the effect of human thermal adaptation on the acceptable temperature-humidity zone in hot-humid conditions, further studies should be conducted combining the relation of air humidity and human health when designing the appropriate indoor thermal environments in hothumid regions.

\section{Conclusions}

This paper presents a theoretical and experimental study to reveal the impact of air humidity on acceptable temperatures in hot environments. The results validated that the relative humidity has a significant effect on human physiological responses and subjective thermal perceptions when the temperature is above $30^{\circ} \mathrm{C}$. There is a significant correlation of MST and TSV when the air temperature is below $30^{\circ} \mathrm{C}$ but little correlation is found when the temperature increases, and the higher air humidity further contributed to the dispersed relationship between MST and TSV.

Our previous and existing studies demonstrate that people living in hot-humid environments have higher acclimatization and tolerance due to thermal adaptation. The SET model failed to reflect the human long-term physiological acclimatization and psychological adaptation to high humidity in hot conditions. Accordingly, a humidity correction coefficient $e_{R H}$ is proposed to modify the deviation of the predicted SET caused by different humidity levels, and is expressed as a function of $\delta S E T_{R H}$. Based on the modified method, the acceptable air temperatures under different relative 
humidity levels with clothing insulation of 0.32 clo and 0.5 clo are obtained, and the acceptable temperature-humidity zone is therefore drawn.

A comparison of the acceptable temperature limits with and without the correction coefficient shows that the upper acceptable temperatures are raised using the modified SET model. The modified model fills the gaps in which the SET model could not reflect the human thermal adaption and the present adaptive models fail to quantify the impact of air humidity. It is revealed that the acceptable temperatures decrease with increasing humidity for both models with and without thermal adaptation modification.

The proposed method of the modified SET would be referred for ensuring a comfortable indoor thermal environment and promoting the energy efficiency in buildings when considering human long-term thermal adaption in hot-humid regions.

Future studies will include changing variables of indoor air velocity, metabolism rate as well as the account of the radiation temperature.

\section{Acknowledgements}

The completion of this paper is financially funded by the National Natural Science Foundation of China (Grant No: 51561135002) and the Natural Science Foundation of Jiangsu Province (BK20130946); The data source was from the project (Grant No: 50838009) funded by the National Natural Science Foundation of China. The authors would like to thank the support from 111 Project (No.B13041); the student and the volunteer subjects who were involved a long-term experimental study.

\section{References:}

[1] F.C.Y.C. Houghten, Determining lines of equal comfort, ASHRAE Trans. 29(1923)163-176.

[2] H. Liu, Y. Wu, B. Li, Y. Cheng, R. Yao, Seasonal variation of thermal sensations in residential buildings in the Hot Summer and Cold Winter zone of China, Energ Buildings. 140(2017)9-18.

[3] Y. Zhang, J. Wang, H. Chen, J. Zhang, Q. Meng, Thermal comfort in naturally ventilated buildings in hot-humid area of China, Build Environ. 45(11)(2010)2562-2570.

[4] B. Li, W. Yu, M. Liu, N. Li, Climatic Strategies of Indoor Thermal Environment for Residential Buildings in Yangtze River Region, China, Indoor Built Environ. 20(1)(2011)101-111. 
[5] H. Yan, Y. Mao, L. Yang, Thermal adaptive models in the residential buildings in different climate zones of Eastern China, Energ Buildings. 141(2017)28-38.

[6] C.P. Yaglou, Indices of comfort, In Physiology of Heat Regulation and the Science of Clothing. Ed. Newburgh, L.H.(1949)227-287.

[7] N. Glickman, T. Inouye, R.W. Keeton, M.F. Fahnestock, Physiological examination of the effective temperature index, Heating Piping and Air Conditioning. 22(1950)157-164.

[8] W.J.B.H. Koch, Is humidity important in the temperature comfort range? ASHRAE Trans. 4(2)(1960)63-68.

[9] R.G. Nevins, F.H. Rohles, W. Springer, A.M. Feyerherm, A temperature-humidity chart for thermal comfort of seated persons, ASHRAE Trans. 72(1)(1966)283-291.

[10] W. Koch, B. Jennings, M. Humphreys, Environmental study II-sensation responses to temperature and humidity under still air conditions in the comfort range.1960

[11] P.E. McNall, F.H.R. Jaax, R.G. Nevins, Thermal comfort (thermally neutral) conditions for three levels of activity, ASHRAE Trans. 1(73)(1967)1-14.

[12] K. Hayakawa, N. Isoda, T. Yanase, Study of the effects of air temperature and humidity on the human body during physical exercise in the summer, Journal of Architecture, Planning, and Environmental Engineering. (1989)47-55.

[13] L. Berglund.Comfort criteria and humidity standards. the Pan-Pacific Symposium on Building and Urban Environmental Conditioning in Asia.1995-03-16,1995.

[14] H. Kubo, N. Isoda, H. Enomoto-Koshimizu, Cooling effects of preferred air velocity in muggy conditions, Build Environ. 32(3)(1997)211-218.

[15] Y.Y. Tian, Study on human thermal responses in warm and humid environments. Beijing: Tsinghua University, 2001.

[16] R.J. Maughan, H. Otani, P. Watson, Influence of relative humidity on prolonged exercise capacity in a warm environment, Eur J Appl Physiol. 112(6)(2012)2313-2321.

[17] A.P.C. Chan, W. Yi, D.P. Wong, M.C.H. Yam, D.W.M. Chan, Determining an optimal recovery time for construction rebar workers after working to exhaustion in a hot and humid environment, Build Environ. 58(4)(2012)163-171.

[18] J. Zhao, N. Zhu, S. Lu, Productivity model in hot and humid environment based on heat tolerance time analysis, Build Environ. 44(11)(2009)2202-2207.

[19] D. Shen, N. Zhu, Influence of the temperature and relative humidity on human heat acclimatization during training in extremely hot environments, Build Environ. 94(2)(2015)1-11.

[20] J. Malchaire, A. Piette, B. Kampmann, P. Mehnert, H. Gebhardt, G. Havenith, E.D. Hartog, I. Holmer, K. Parsons, G. Alfano, Development and validation of the predicted heat strain model, Ann Occup Hyg. 45(2)(2001)123-135.

[21] G.M. Budd, Wet-bulb globe temperature (WBGT)--its history and its limitations, Journal of Science \& Medicine in Sport. 11(1)(2008)20.

[22] ISO 7243: 1982, Hot environments - Estimation of the heat stress on working man, based on the WBGT-index (wet bulb globe temperature). 1982

[23] ISO 7933: 2004, Ergonomics of the thermal environment - Analytical determination and interpretation of heat stress using calculation of the predicted heat strain, International Standardisation Orginasation, 2004.

[24] C.G. Bornehag, J. Sundell, L. Hagerhed-Engman, T. Sigsggard, S. Janson, N. Aberg, D.S. Group, 'Dampness' at home and its association with airway, nose, and skin symptoms among 
10,851 preschool children in Sweden: a cross-sectional study, Indoor Air. 15(S10)(2005)48-55.

[25] M. Simoni, E. Lombardi, G. Berti, F. Rusconi, G.S. La, S. Piffer, M.G. Petronio, C. Galassi, F. Forastiere, G. Viegi, Mould/dampness exposure at home is associated with respiratory disorders in Italian children and adolescents: the SIDRIA-2 Study, Occup Environ Med. 62(9)(2005)616-622.

[26] K.W. Tham, M.S. Zuraimi, D. Koh, F.T. Chew, P.L. Ooi, Association between home dampness and presence of molds with asthma and allergic symptoms among young children in the tropics, Pediatr Allergy Immu. 18(5)(2007)418-424.

[27] J. Li, M. Cleveland, L.D. Ziemba, R.J. Griffin, K.C. Barsanti, J.F. Pankow, Q. Ying, Modeling regional secondary organic aerosol using the Master Chemical Mechanism, Atmos Environ. 102(102)(2015)52-61.

[28] A.G. Carlton, C. Wiedinmyer, J.H. Kroll, A review of Secondary Organic Aerosol (SOA) formation from isoprene, Atmospheric Chemistry \& Physics. 9(2)(2009)4987-5005.

[29] M.K. Nematchoua, R. Tchinda, J.A. Orosa, W.A. Andreasi, Effect of wall construction materials over indoor air quality in humid and hot climate, Journal of Building Engineering. 3(2015)16-23.

[30] W. Cui, Q. Ouyang, Y. Zhu, Field study of thermal environment spatial distribution and passenger local thermal comfort in aircraft cabin, Build Environ. 80(10)(2014)213-220.

[31] L. Pang, Q. Yue, L. Dong, L. Meng, Thermal comfort assessment in civil aircraft cabins, Chinese J Aeronaut. 27(2)(2014)210-216.

[32] S.I. Tanabe, K.I. Kimura, Effects of air temperature, humidity, and air movement on thermal comfort under hot and humid conditions, ASHRAE Trans. 100(2)(1994)953-969.

[33] H. Djamila, S. Kumaresan, C.M. Chu, Effect of Humidity on Thermal Comfort in the Humid Tropics, Journal of Building Construction \& Planning Research. 02(2)(2014)109-117.

[34] L. Jin, Y. Zhang, Z. Zhang, Human responses to high humidity in elevated temperatures for people in hot-humid climates, Build Environ. 114(2017)257-266.

[35] H. Tsutsumi, S.I. Tanabe, J. Harigaya, Y. Iguchi, G. Nakamura, Effect of humidity on human comfort and productivity after step changes from warm and humid environment, Build Environ. 42(12)(2007)4034-4042.

[36] S. Jing, B. Li, M. Tan, H. Liu, Impact of Relative Humidity on Thermal Comfort in a Warm Environment, Indoor Built Environ. 22(4)(2013)598-607.

[37] C. Li, H. Liu, B. Li, Y. Cheng, C. Du, A. Sheng, Human responses to the air relative humidity ramps: A chamber study, Build Environ. 123(2017)458-468.

[38] M.E. Fountain, E. Arens, T.E. Xu, F.S. Bauman, M. Oguru, An investigation of thermal comfort at high humidities, Center for the Built Environment.1999

[39] ASHRAE 55: 2004, Thermal Environmental Conditions for Human Occupancy. 2004

[40] ASHRAE 55: 2013, Thermal Environmental Conditions for Human Occupancy. 2013

[41] ISO 7730: 2005, Ergonomics of the thermal environment - Analytical determination and interpretation of thermal comfort using calculation of the PMV and PPD indices and local thermal comfort criteria. 2005

[42] J. Toftum, A.S. Jørgensen, P.O. Fanger, Upper limits for indoor air humidity to avoid uncomfortably humid skin, Energ Buildings. 28(1)(1998)1-13.

[43] A.P. Gagge, A.P. Fobelets, L. Berglund, A standard predictive index of human response to the thermal environment, ASHRAE Trans. 92(2B)(1986)709-731.

[44] J. Gao, Y. Wang, P. Wargocki, Comparative analysis of modified PMV models and SET 
models to predict human thermal sensation in naturally ventilated buildings, Build Environ. 92(2015)200-208.

[45] R. Yao, B. Li, J. Liu, A theoretical adaptive model of thermal comfort - Adaptive Predicted MeanVote(aPMV), Build Environ. 44(10)(2009)2089-2096.

[46] K.C. Parsons, Human thermal environments: the effect of hot, moderate, and cold environments on human health, comfort and performance. Taylor and Francis, Lodon, 2013.

[47] I. Griffths.Thermal comfort studies in buildings with passive solar features. the Commission of the European Community.U.K.1990.

[48] A.P. Gagge, An Effective Temperature Scale Based on a Simple Model of Human Physiological Regulatory Response, ASHRAE Trans. 77(1)(1971)21-36.

[49] W.M.A. WMA, WMA Declaration of Helsinki - Ethical Principles for Medical Research Involving Human Subjects, World Medical Journal. 27(2)(2008)235-237.

[50] C.M.I. Centre, The Dedicated Meteorological Data Set for the Analysis of Building Thermal Environment in China. Beijing, China Construction Industry Publish House, 2005.

[51] Y. Yang, B. Li, H. Liu, M. Tan, R. Yao, A study of adaptive thermal comfort in a wellcontrolled climate chamber, Appl Therm Eng. 76(2015)283-291.

[52] F. Faul, E. Erdfelder, A.G. Lang, A. Buchner, G*Power 3: a flexible statistical power analysis program for the social, behavioral, and biomedical sciences., Behavior Research Methods. 39(2)(2007)175-191.

[53] A.P. Gagge, Y. Nishi, Heat Exchange Between Human Skin Surface and Thermal Environment, Compr Physiol.2010

[54] M. Luo, X. Zhou, Y. Zhu, J. Sundell, Revisiting an overlooked parameter in thermal comfort studies, the metabolic rate, Energ Buildings. 118(2016)152-159.

[55] Tanabe, S., H. Imamura, Q. Jiang, and T. Suzuki, Effects of humidity on thermal comfort in office space : Part 4 Subjective experimental results under equivalent SET*conditions, Proceedings of ASHRAE Technical Conference, Hiroshima. 7(1995)689-692.

[56] M.A. Humphreys, J.F. Nicol, I.A. Raja, Field Studies of Indoor Thermal Comfort and the Progress of the Adaptive Approach, Advances in Building Energy Research. 1(1)(2006)55-88.

[57] R.J.D. Dear, A Global Database of Thermal Comfort Field Experiments, ASHRAE Trans. 104(1998)1141-1152.

[58] J.F. Nicol, I.A. Raja, A. Allaudin, G.N. Jamy, Climatic variations in comfortable temperatures: the Pakistan projects, Energ Buildings. 30(3)(1999)261-279.

[59] K.J. Mccartney, J.F. Nicol, Developing an adaptive control algorithm for Europe, Energ Buildings. 34(6)(2002)623-635.

[60] F. Nicol, M. Humphreys, Derivation of the adaptive equations for thermal comfort in freerunning buildings in European standard EN15251, Build Environ. 45(1)(2010)11-17.

[61] R. Yao, B. Li, K. Steemers, A. Short, Assessing the natural ventilation cooling potential of office buildings in different climate zones in China, Renew Energ. 34(12)(2009)2697-2705.

[62] D. Fiala, K.J. Lomas, M. Stohrer, First Principles Modeling of Thermal Sensation Responses in Steady-State and Transient Conditions, ASHRAE Trans. 109(1)(2003)179-186.

[63] D. Wang, H. Zhang, E. Arens, C. Huizenga, Observations of upper-extremity skin temperature and corresponding overall-body thermal sensations and comfort, Build Environ. 42(12)(2007)39333943.

[64] B. Li, W. Li, H. Liu, R. Yao, M. Tan, S. Jing, X. Ma, Physiological Expression of Human 
Thermal Comfort to Indoor Operative Temperature in the Non-HVAC Environment, Indoor Built Environ. 19(2)(2010)221-229.

[65] C. Chun, A. Kwok, T. Mitamura, N. Miwa, A. Tamura, Thermal diary: Connecting temperature history to indoor comfort, Build Environ. 43(5)(2008)877-885.

[66] J. Yu, G. Cao, W. Cui, Q. Ouyang, Y. Zhu, People who live in a cold climate: thermal adaptation differences based on availability of heating, Indoor Air. 23(4)(2013)303.

[67] M. Luo, W. Ji, B. Cao, Q. Ouyang, Y. Zhu, Indoor climate and thermal physiological adaptation: Evidences from migrants with different cold indoor exposures, Build Environ. 98(2016)30-38.

[68] B. Li, Y. Yang, R. Yao, H. Liu, Y. Li, A simplified thermoregulation model of the human body in warm conditions, Appl Ergon. 59(Pt A)(2017)387-400.

[69] J. Toftum, A.S. Jørgensen, P.O. Fanger, Upper limits of air humidity for preventing warm respiratory discomfort, Energ Buildings. 28(1)(1998)15-23.

[70] S. Lin, M. Luo, R.J. Walker, X. Liu, S.A. Hwang, R. Chinery, Extreme high temperatures and hospital admissions for respiratory and cardiovascular diseases, Epidemiology. 20(5)(2009)738-746.

[71] G. Richardson, S. Eick, R. Jones, How is the indoor environment related to asthma?: literature review, J Adv Nurs. 52(3)(2005)328-339.

[72] H.D. Jr, M.A. Jhaveri, D.M. Mannino, H. Strawbridge, J. Temprano, The effect of mold sensitization and humidity upon allergic asthma, Clin Respir J. 7(2)(2012)135-144.

[73] T. Zhang, X. Liu, Y. Jiang, Development of temperature and humidity independent control (THIC) air-conditioning systems in China-A review, Renew Sust Energ Rev. 29(7)(2014)793-803. [74] A.A. Aziz, D. Sumiyoshi, Y. Akashi, Low cost humidity controlled air-conditioning system for building energy savings in tropical climate, Journal of Building Engineering.(2017)9-16. 